\title{
Using the Spatial Distribution of Installers to Define Solar Photovoltaic Markets
}

Eric 0'Shaughnessy ${ }^{1}$, Gregory F. Nemet ${ }^{2}$, and Naïm Darghouth ${ }^{3}$

${ }^{1}$ National Renewable Energy Laboratory; ${ }^{2}$ University of Wisconsin at Madison; ${ }^{3}$ Lawrence Berkeley National Laboratory
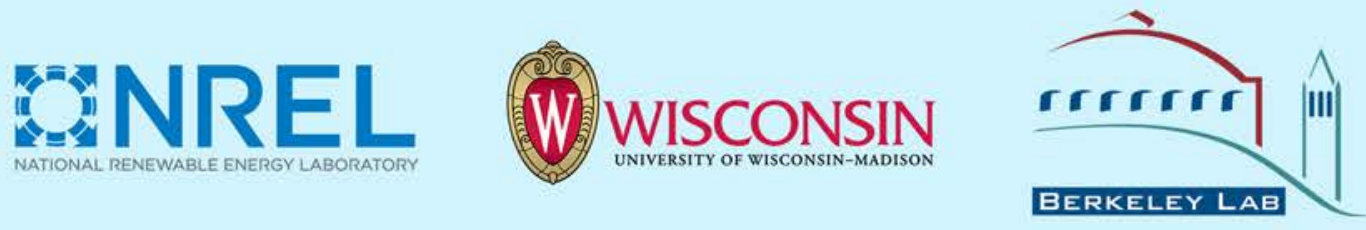

\section{IIImin Sunshot}

September 2016

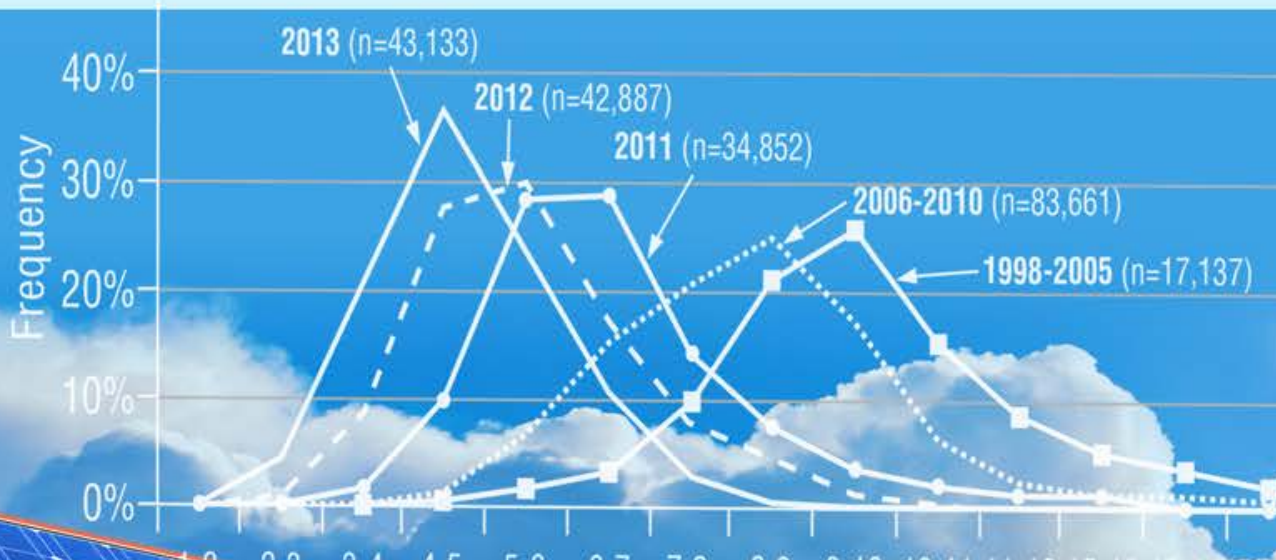

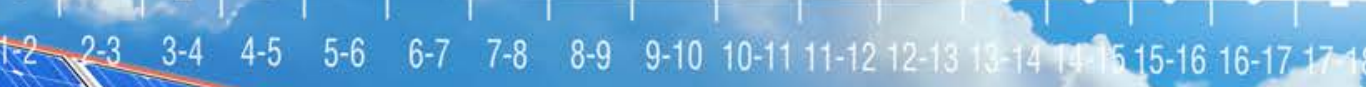
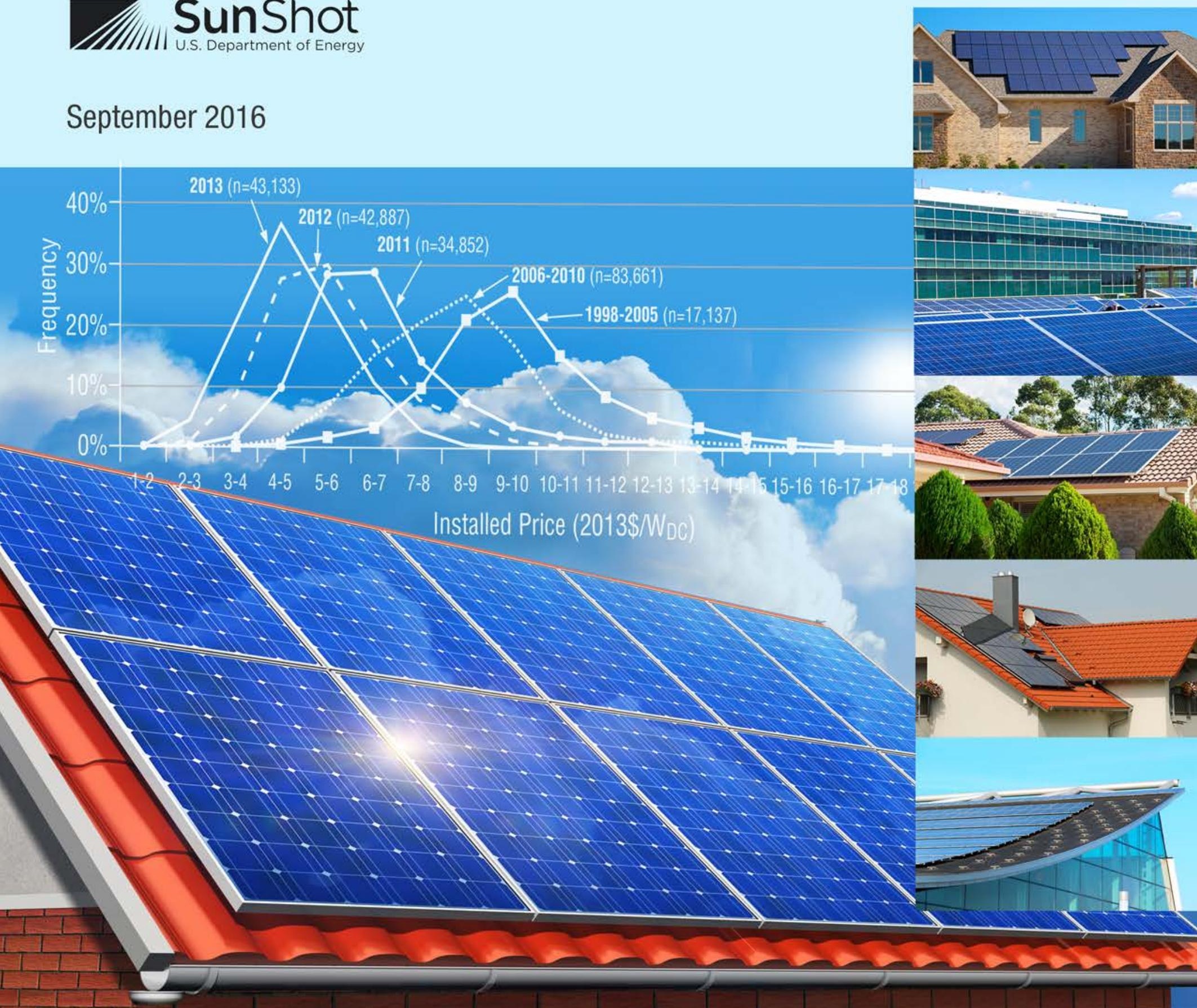


\title{
Using the Spatial Distribution of Installers to Define Solar Photovoltaic Markets
}

\author{
Eric 0'Shaughnessy ${ }^{1}$, Gregory F. Nemet ${ }^{2}$, and Naïm Darghouth ${ }^{3}$ \\ ${ }^{1}$ National Renewable Energy Laboratory; ${ }^{2}$ University of Wisconsin at Madison; \\ 3 Lawrence Berkeley National Laboratory
}

\section{Contents}

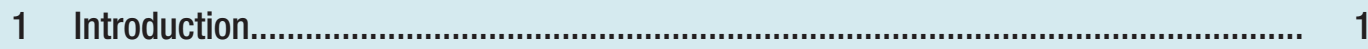

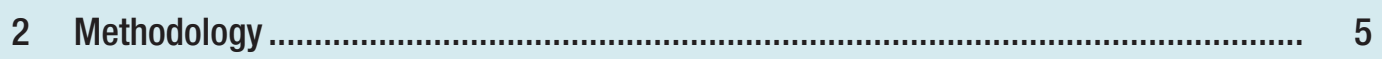

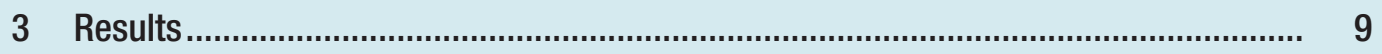

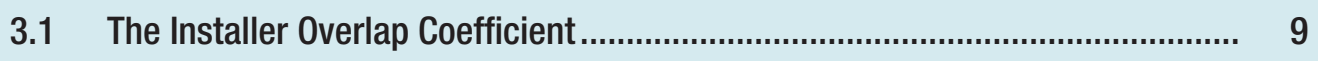

3.2 Market Outcomes.................................................................................... 11

3.3 Measures of Competition under Market Outcomes....................................... 14

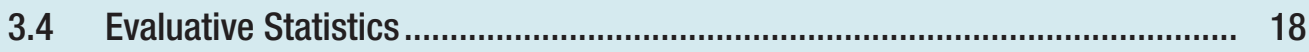

3.5 Using the IOC to Understand the Spatial Distribution of Installers.................... 23

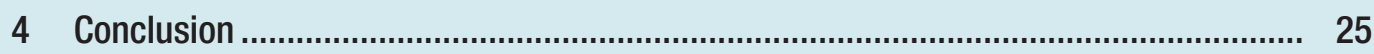

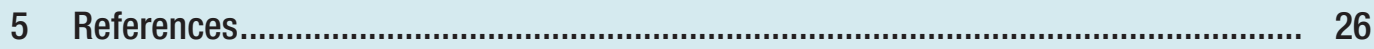

\section{List of Figures and Tables}

Figure ES-1. Illustration of differences in solar PV markets through a county-level approach (left map) and installer-based approach (right map) in the greater Phoenix area. Each color represents a separate market. Gray boundaries correspond to zip codes

Figure ES-2. Systems installed by two example installers in southern Los Angeles County

Figure 1. System clustering across jurisdictional (county) boundaries

Figure 2. Schematic of the IOC calculation.

Figure 3. Visualization of the IOC algorithm in Sacramento County

Figure 4. Mean IOC between zip codes and their Kth nearest neighbor zip code with $95 \%$ confidence interval in gray

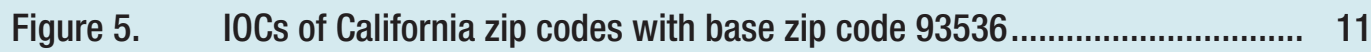

Figure 7. Illustrations of market outcomes for three example regions. 


\section{List of Figures and Tables (cont.)}

Figure 8. Visualization of installer market share measured at the county level (left panel) and IOC market level (right panel).

Figure 9. Local market shares (CS specification) compared to county-level market shares for four example installers in Los Angeles County

Figure 10. Distributions of $\mathrm{HHI}$ under different market definitions

Figure 11. Moran scatterplots for spatially lagged install prices

Figure 12. Moran scatterplots for spatially lagged installer density

Figure 13. Moran's I spatial correlograms for install prices (left panel) and installer density (right panel) with 95\% confidence intervals in gray

Figure 14. Market size as a function of installer diversity (CS specification).

Figure 15. Density (systems $/ \mathrm{km}^{2}$ ) of systems installed by national-scale installer (left map) and local installers (right map)

Table 1. Summary of IOC Market Specifications

Table 2. $\quad$ PV Market Definition Outcomes.

Table 3. Spatial Weights Matrices Definitions for Moran's I Tests.

Table 4. Moran's I Test Results (Z statistics in parentheses) 20

Table 5. Moran's I Test Results with Inverse Distance Weighting (Z statistics in parentheses)

(1)
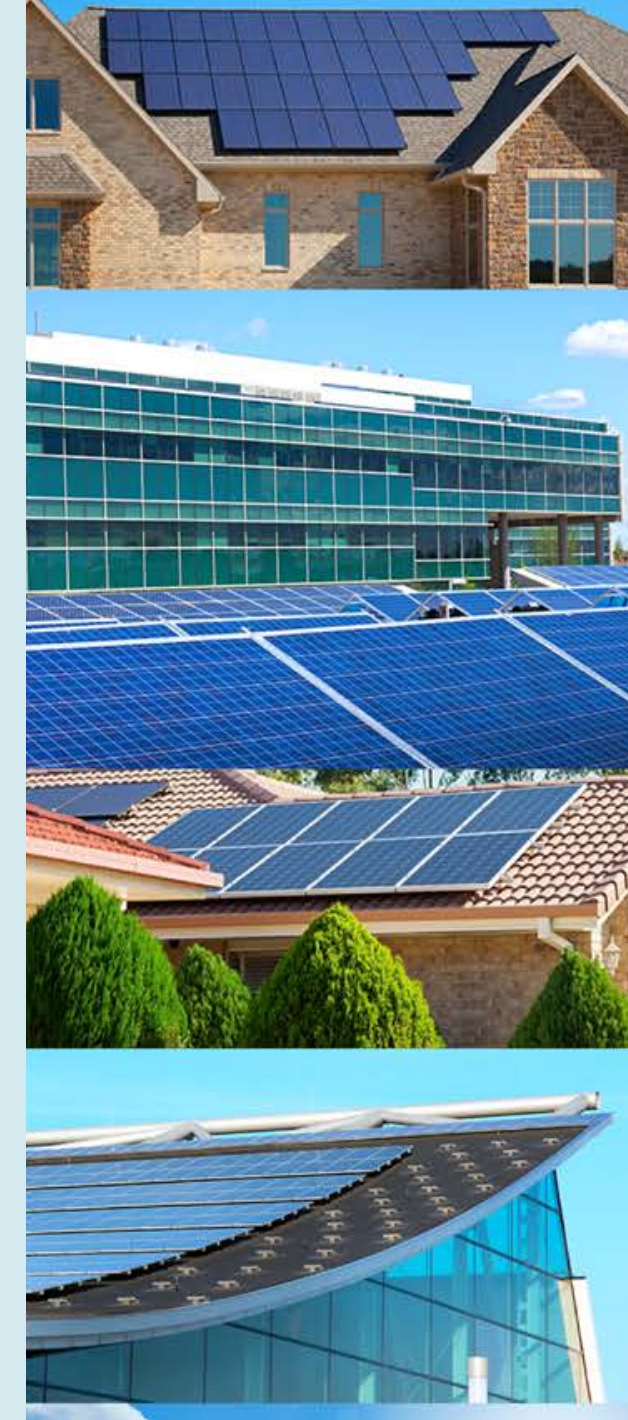


\section{Executive Summary}

A growing body of research seeks to explore the effects of solar photovoltaic (PV) market dynamics on competition and ultimately on prices. Researchers have found significant associations between installed system prices and PV industry concentration, numbers of installers, and installer size and experience (Wiser et al. 2007; Barbose et al. 2015; Gillingham et al. 2016; Nemet et al. 2016). However, the use of jurisdictional boundaries (e.g., zip code, county, state) as proxies for market boundaries may misrepresent the true market structure and limit understanding of solar PV market competition, firm relationships, and price trends.

This paper develops an approach to delineate solar PV market boundaries based on the spatial distribution of installer firms. The basic premise of the approach is that the extent to which different installer firms exert price constraints on one another may be inferred from their spatial distributions. We develop an algorithm based on an installer overlap coefficient (IOC) that calculates the percentage of installers that are shared between multiple geographic areas. The IOC algorithm allows us to delineate solar PV market boundaries around clusters of local installer communities (Figure ES-1).

Markets in greater Phoenix area through countylevel approach

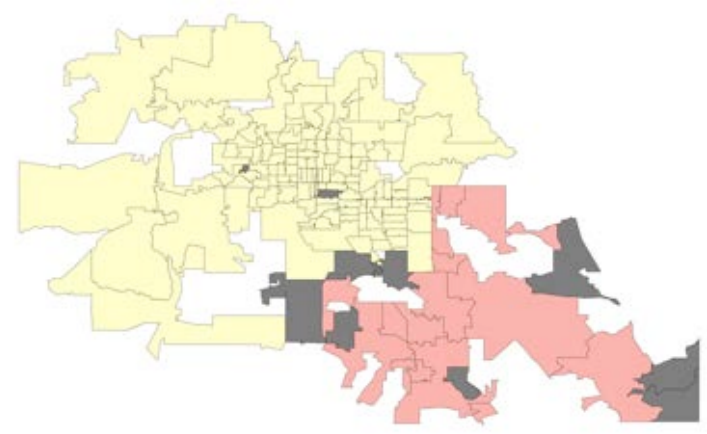

Markets in greater Phoenix area through installerbased approach

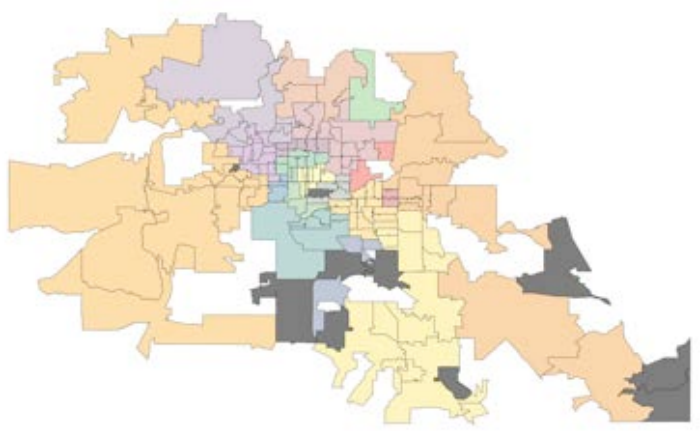

Figure ES-1. Illustration of differences in solar PV markets through a county-level approach (left map) and installer-based approach (right map) in the greater Phoenix area. Each color represents a separate market. Gray boundaries correspond to zip codes.

Note: Gray areas are excluded from the analysis.

The installer-based approach exhibits several desirable properties. First, the IOC demonstrates that installer communities become increasingly dissimilar at greater geographic distances, suggesting that a county-level approach to market definition may be overly broad. Second, the IOC approach produces more market granularity than the county-level approach (Figure ES-2). Increased market granularity may allow future PV market research to study the role of local market dynamics on pricing with more precision. Third, spatial statistics demonstrate that spatial correlations in market metrics, such as installed prices, decrease with distance and that installerbased markets may better capture highly local market spatial correlations. 


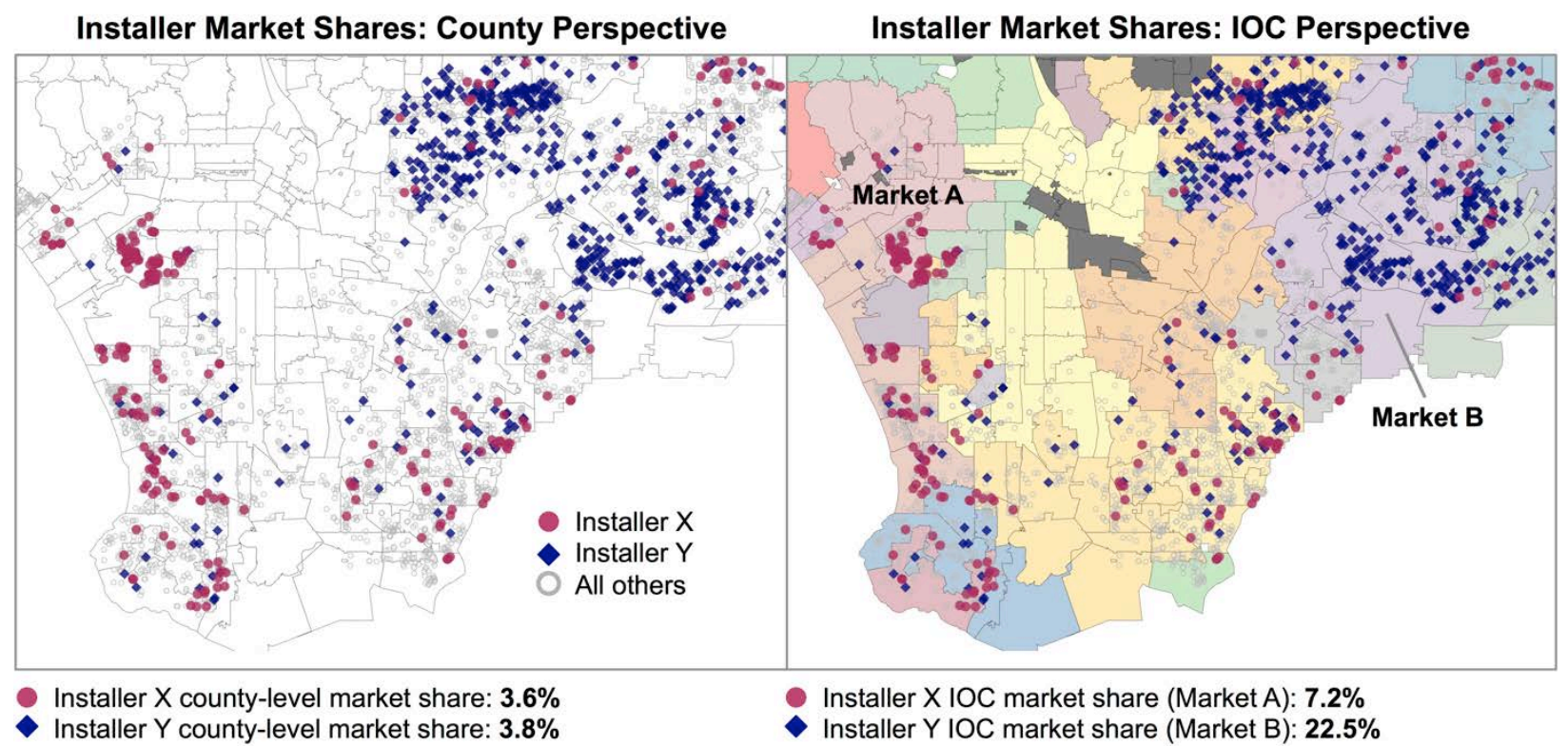

Figure ES-2. Systems installed by two example installers in southern Los Angeles County.

The market shares of installers $X$ and $Y$ measured at the county level (left map) may misrepresent local market shares due to the clustering of systems by installers $X$ and $Y$ below the county level. The installerbased approach to $\mathrm{PV}$ market definition (right map) reveals that the local market share of installer $\mathrm{Y}$ is more than three times greater in pockets of southeastern Los Angeles County than at the county level.

These analyses demonstrate the importance of an accurate market definition. Spatial statistical tests show high degrees of spatial correlation in market variables such as installed price and installer density. The source of these spatial relationships remains unclear, though local policies likely play a role. In any case, a more accurate representation of PV market boundaries that does not arbitrarily rely on jurisdictional boundaries may improve our ability to study and understand the diverse market factors that drive geographic price dispersion in solar PV markets. 


\section{Introduction}

The rapid evolution of distributed solar photovoltaic (PV) installation markets has prompted researchers to explore the effects of PV market dynamics on competition and ultimately on prices. Recent work has found significant associations between installed system prices and PV industry concentration, numbers of installers, and installer scale and experience (Wiser et al. 2007; Barbose et al. 2015; Gillingham et al. 2016; Nemet et al. 2016). However, all of these and other variables require defining geographical boundaries for these activities. The reliability of PV market research results is limited by the approach used to define PV installation markets. An accurate representation of the geographic boundaries of markets underpins market-level analyses, yet a consensus on the appropriate method for the geographic delineation of markets has remained elusive (Brooks 1995; Brorsen et al. 1997; Massey 2000; Davis and Garces 2010; Kaplow 2015). The use of jurisdictional boundaries (e.g., zip code, county, state) may misrepresent the true market structure and limit our understanding of market competition, firm relationships, and price trends (Brooks 1995). In this paper, we seek to develop a PV market definition approach that more accurately characterizes the geographic boundaries of PV markets based on the spatial distribution of PV installer firms. We compare the results of the installerbased approach to a county-level market definition, the most commonly used method. We then evaluate the installer-based market definition using spatial statistical methods that measure the degree of spatial dependence in PV market variables (e.g., install prices) between areas within defined market boundaries.

Before proceeding to a review of market definition in practice, a more general discussion of the motivation behind PV market definition is merited. Solar PV systems tend to cluster in areas of high PV demand due to several factors (e.g., income, peer effects), and these clusters can defy jurisdictional boundaries (Figure 1) (Bollinger and Gillingham 2012). The tendency of product clustering gives rise to the spatial interdependence of firms and raises questions of how the interactions of economic agents shape collective behavior and market patterns (Brorsen et al. 1997; Anselin 2001). In the case of PV markets, various installer communities have emerged to serve geographically dispersed clusters of prospective PV customers. PV market clustering results in various degrees of installer competition in different areas, driving geographic price dispersion (Wiser et al. 2007; Barbose et al. 2015). Solar PV market research based on jurisdictional boundaries can arbitrarily split PV customer clusters or alternatively exaggerate a market's geographic size. Further, solar PV markets are unique in several ways from markets for other homogenous goods. The majority of solar installers are small local businesses; however, the majority of PV systems are installed by large installers operating at a multi-state or national scale (Nemet et al. 2016). This dichotomy could produce interesting market dynamics where small, local-scale installers directly compete with large, national-scale installers. Our understanding of how local presence and installer scale affect PV markets begins with an appropriate representation of market boundaries. 


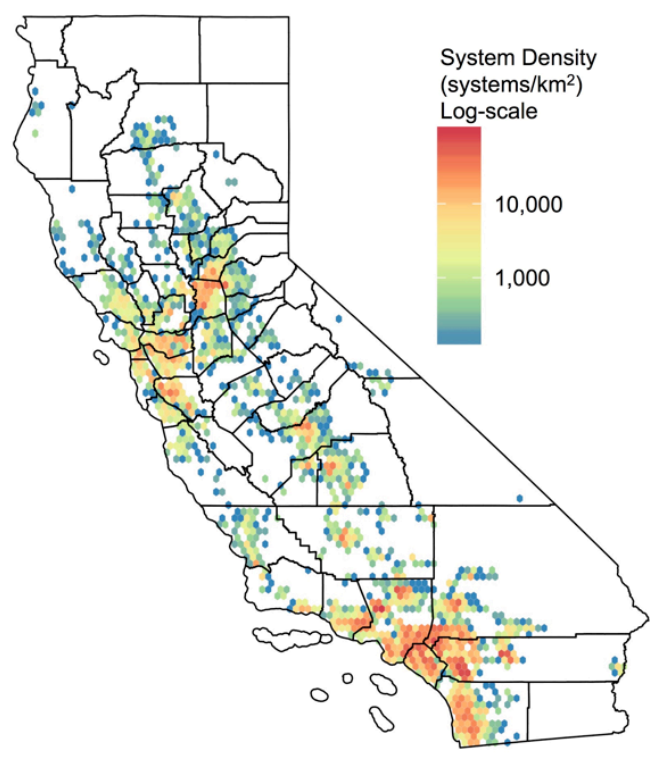

Figure 1. System clustering across jurisdictional (county) boundaries

Although a "market" is a fundamental economic concept — and one with high-stakes real world applications such as anti-trust decisions - there is no single definition for what constitutes a market, nor any consensus approach on how markets should be defined geographically (Brooks 1995; Massey 2000; Kaplow 2015). The theoretical foundation of most market definition research is the delineation of market boundaries based on product substitutability (Massey 2000; Baker 2007; Davis and Garces 2010; Boshoff 2014). Formally, product substitutability can be modeled as a demand- or supply-side response in one good to a price change in another good:

$$
e_{x, y}=\frac{\partial \log \left(Q_{x}\right)}{\partial \log \left(P_{y}\right)}
$$

Where $e_{x, y}$ is the cross-price elasticity of good $x$ with respect to good $y, Q_{x}$ is the quantity demanded or supplied of $\operatorname{good} x$, and $P_{y}$ is the price of good $y$. Product substitutability $\left(e_{x, y}>0\right)$ is one basis to indicate that two products $x$ and $y$ belong to the same market. For example, solar PV systems and small wind power systems may be defined as sharing a market because an increase in prices for solar PV systems may increase demand for small wind power systems, i.e., wind power systems are a substitute for solar PV. Similarly, the products of two installers that operate in the same city may also be viewed as sharing a market because an increase in one installer's prices may drive customers to purchase systems from the competing installer.

The challenge of market definition then becomes a problem of (a) inferring product substitutability from observed economic activity (Geroski 1998; Boshoff 2014) and (b) determining a threshold of product substitutability at which two products belong to the same market. Product characteristics and the conduct of firms are two possible sources of evidence for product substitutability (Baker 2007). Product characteristics, including shipping costs and the geographic distribution of customers, could provide evidence of product substitutability between geographic areas. In general, two adjacent areas constitute a single market for a homogenous good with low shipping costs because customers in one area could easily respond to price changes by switching to goods in the adjacent region. However, two geographically distant areas 
could constitute separate markets for a homogeneous good if shipping costs are high enough that substitution between the two areas is cost-prohibitive. The conduct of firms is another possible source of evidence on product substitutability to the extent that the conduct of firms reveals how demand-side substitution is understood by firms (Baker 2007). Evidence of how firms respond to the products and location of their closest competitors may be used to infer product substitutability (Baker 2007).

The magnitude of product substitutability $\left(e_{x, y}\right)$ that defines market integration is not clearly defined (Massey 2000; Baker 2007; Kate and Niels 2008; Boshoff 2014). A commonly utilized measure, especially for antitrust purposes, is the degree to which competing firms exert price constraints on one another (Baker 2007; Beckert 2010; Boshoff 2014). This type of firm-based approach is supported by economic theory, which suggests that firms are price takers in competitive markets for homogenous products due to the price constraints exerted by competitors in the same market (Perloff 2009). The U.S. Department of Justice hypothetical monopolist test (HMT), based on competitive price constraints, is the standard market definition for U.S. antitrust purposes (Coate and Fischer 2008). The HMT is an algorithm that defines a market as the product or geographic area over which a hypothetical monopolist could profitably exercise a "small, but significant, non-transitory increase in price" (SSNIP). The HMT begins with the identification of a "candidate" market then asks whether a hypothetical monopolist could profitably exercise the SSNIP. The algorithm proceeds by adding additional areas to the candidate market until the SSNIP becomes profitable. Extrapolating the HMT to a community of firms, a market could be defined as the geographic area over which the collective action of all firms in the area could result in profit maximizing prices above competitive prices (Werden 1981). So, a market boundary may exist where the firms in one area cease to represent the firms in an adjacent area.

This paper pursues a firm-based approach to PV market definition for three reasons. First, the spatial variability of installer communities, with a heterogeneous mix of local- and national-scale installers, lends itself well to the demarcation of market boundaries based on distinct groups of installers that exert localized price constraints on one another. Second, a price-based approach to PV market definition risks false conclusions due to shared trends between markets, given that price-based market definitions are sensitive to price trend coincidence across markets (Davis and Garces 2010). A price-based approach would require the removal of consistently downward national trends in PV prices that occurred throughout the United States over the past several decades. Although de-trending is theoretically possible, we opt for the simplicity of a firm-based approach in the present study. Third, part of the goal of our market definition is to understand solar PV system price variability. Thus a price-based approach could result in spurious market research by defining market boundaries based on the subject of research (i.e., prices).

The primary goal of this paper is to describe an installer-based methodology for solar PV market definition to be used in future solar PV market research. ${ }^{1}$ We then assess the outcome of the installer-based market definition by evaluating differences in market research outcomes between the installer-based and county-based approaches. Several desirable properties of the installer-

\footnotetext{
${ }^{1}$ This paper is part of a larger body of research conducted by Lawrence Berkeley National Laboratory (LBNL), the University of Texas at Austin, the University of Wisconsin-Madison, the National Renewable Energy Laboratory, and Yale University. The research more broadly explores PV system price variability in the United States.
} 
based approach are demonstrated. Although the primary use of this methodology is as a tool for future market research, the outcomes of the installer-based market approach are also illustrative of the U.S. solar PV installer community. We therefore include a discussion of how the installerbased market definition approach allows a visualization of the U.S. PV installer community as a mix of small local-scale and large national-scale firms. 


\section{Methodology}

This study uses installed system data from the Lawrence Berkeley National Laboratory's "Tracking the Sun" (TTS) data set (Barbose and Darghouth 2015). The full TTS covers about two-thirds of U.S. PV installations since 2000. The data used in this study include 134,078 systems smaller than $15 \mathrm{~kW}$ installed between January 1, 2013 and December 31, 2014 by an installer firm, that is, the data set excludes self-installed systems. The systems were installed by 2,867 unique installers in 6,103 zip codes in 22 states.

We develop an installer-based PV market definition approach with two guiding principles. First, solar PV is essentially a homogeneous good with minimal product differentiation; therefore, all installers are potential competitors and may exert competitive price constraints on one another. Second, the degree to which installers exert mutual price constraints may be inferred from their spatial distribution. For example, two installers that are highly active in the same zip code are assumed to exert direct price constraints on one another, while two installers that are exclusively active in two different and geographically distant zip codes are assumed to only exert indirect and weak price constraints on one another. In order to maximize the applicability of this approach in future studies, we use zip codes as the lowest level of geographic granularity. ${ }^{2}$ However, this approach could be modified according to any geographic unit.

Consider a geographic space comprised of $Z$ zip codes $\{x, y, \ldots Z\}$ with $N$ active PV installers $\{i, j, \ldots N\}$. Each zip code $x$ has a set of installers defined by $I_{x}$ :

$$
I_{x}=\{i \in x\}
$$

Where $i$ is an individual installer belonging to installer community $I$. We begin to quantify the degree to which the installer set $I_{x}$ resembles the installer set in another zip code $I_{y}$ by identifying installers that are present in both zip codes. Let $I_{x \cap y}$ represent the set of installers present in both zip codes $x$ and $y$ :

$$
I_{x \cap y}=\{i \in x \mid i \in y\}
$$

We can quantify the percentage of $I_{x}$ found in area $y$ as:

$$
\rho_{x}^{y}=\frac{\# I_{x \cap y}}{\# I_{x}}
$$

Where $\rho_{x}^{y}$ is the percentage of installers in $I_{x}$ also found in $I_{y}, \# I_{x \cap y}$ is the number of installers shared between $I_{x}$ and $I_{y}$, and $\# I_{x}$ is the number of installers in $I_{x}$. The value $\rho_{x}^{y}$ quantifies the degree to which the installer set $I_{y}$ resembles $I_{x}$, but the reverse is not necessarily true. It is possible that a very low value of $\rho_{x}^{y}$ could mask a relatively high value of $\rho_{y}^{x}$ (the percentage of installers in $I_{y}$ also in $I_{x}$ ). We resolve this issue by developing an installer overlap coefficient (IOC) (Figure 2):

\footnotetext{
${ }^{2}$ Lower levels of granularity are theoretically possible through geocoded system coordinates, but geocoding is only possible for a limited number of solar PV systems in the TTS data.
} 


$$
I O C_{x, y}=\rho_{x}^{y} * \rho_{y}^{x}
$$

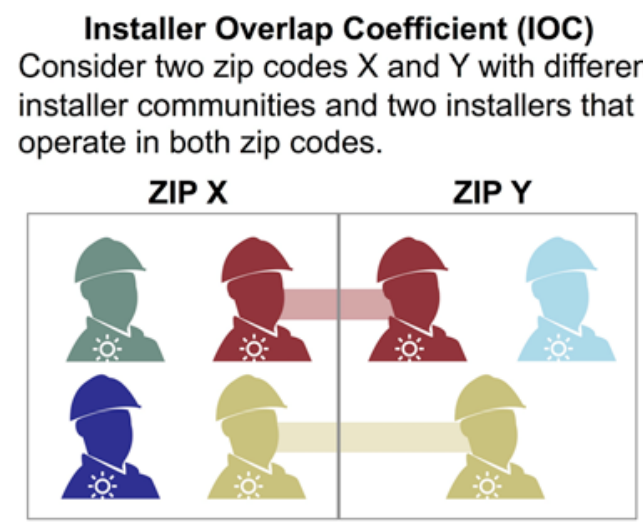

The IOC is the product of the percentage of overlapping installers in both zip codes.

$$
\mathrm{IOC}_{\mathrm{x}, \mathrm{y}}=\frac{2 \mathbf{2} \mathbf{2}}{4 \mathbf{2} \mathbf{2}} \times \frac{2 \mathbf{2} \mathbf{2}}{3 \mathbf{2} \mathbf{2}}=0.33
$$

Figure 2. Schematic of the IOC calculation

The IOC serves as evidence of product substitutability. The essential intuition is that PV customers in either of two zip codes with high shared IOCs can effectively substitute between installers in either zip code. In contrast, in geographically distant zip codes with a low IOC, installers in one zip code are less likely to serve as a substitute for installers in the other zip code. The IOC effectively serves as a proxy for competitive price pressures between zip codes.

The next step is to determine the magnitude of substitutability that determines a common market. For our purposes, the product substitutability threshold is a market definition criterion based on a critical value of the IOC. We define a zip code $y$ as belonging to the same market $M$ as zip code $x$ if the IOC is greater than the market criterion $\mathbb{C}$ :

$$
k \in M_{j}: I O C_{j, k}>\mathbb{C}
$$

In general, a lower value for $\mathbb{C}$ equates to a looser market definition and should result in more market integration, while a higher value for $\mathbb{C}$ indicates more market granularity. The selection of the market criterion is non-trivial because the degree of market granularity directly affects measurements of market power (Massey 2000). We test two market criteria to evaluate PV market definition implications under different levels of market granularity: $\mathbb{C}_{0.25}=0.25 ; \mathbb{C}_{0.01}=$ 0.01. The two criteria were chosen based on the minimum levels of implied installer overlap: $\mathbb{C}_{0.25}$ implies that at least $50 \%$ of installers in at least one of the zip codes are present in the other zip code, and $\mathbb{C}_{0.01}$ implies that at least $10 \%$ of installers in at least one of the zip codes are present in the other zip code. ${ }^{3}$

\footnotetext{
3 There is no extant literature to draw upon for a basis for the market criterion. We therefore model three criteria to assess market outcomes under a range of IOC thresholds.
} 
The next step is to perform an iterative process similar to the HMT algorithm. We developed an algorithm to assign zip codes into candidate markets based on a three step iterative process with two criteria:

1. A candidate market is identified as the zip code with the maximum summed value of IOCs (in theory, installer communities in zip codes with high IOCs should be more integrated with other zip codes than installer communities in zip codes with low IOCs)

2. Zip code centroid coordinates are used to identify the six closest zip codes or "nearest neighbors" to the candidate market. ${ }^{4}$ Note that the six nearest neighbors refer to zip codes with at least one PV install and do not necessarily correspond to the geographically nearest neighbors if the candidate market is surrounded by zip codes with no systems.

3. Additional zip codes are assigned to the candidate market if (a) the IOC with the candidate market exceeds the market criterion $(\mathbb{C})$ and (b) the zip code is in the near neighbor network of the candidate market. The near neighbor network is defined as the network of zip codes that are contiguous with the candidate market through their six nearest neighbors. Functionally, the algorithm identifies the six nearest neighbors of each of the six nearest neighbors of the candidate market $(n=36)$, then assigns zip codes to the candidate market that meet the market criterion $(\mathbb{C})$. The algorithm then repeats that step for the six nearest neighbors of the zip codes assigned to the candidate market in the previous step. Thus, every new zip code assigned to the candidate market is contiguous with the candidate market via zip codes previously assigned (Figure 3 ).

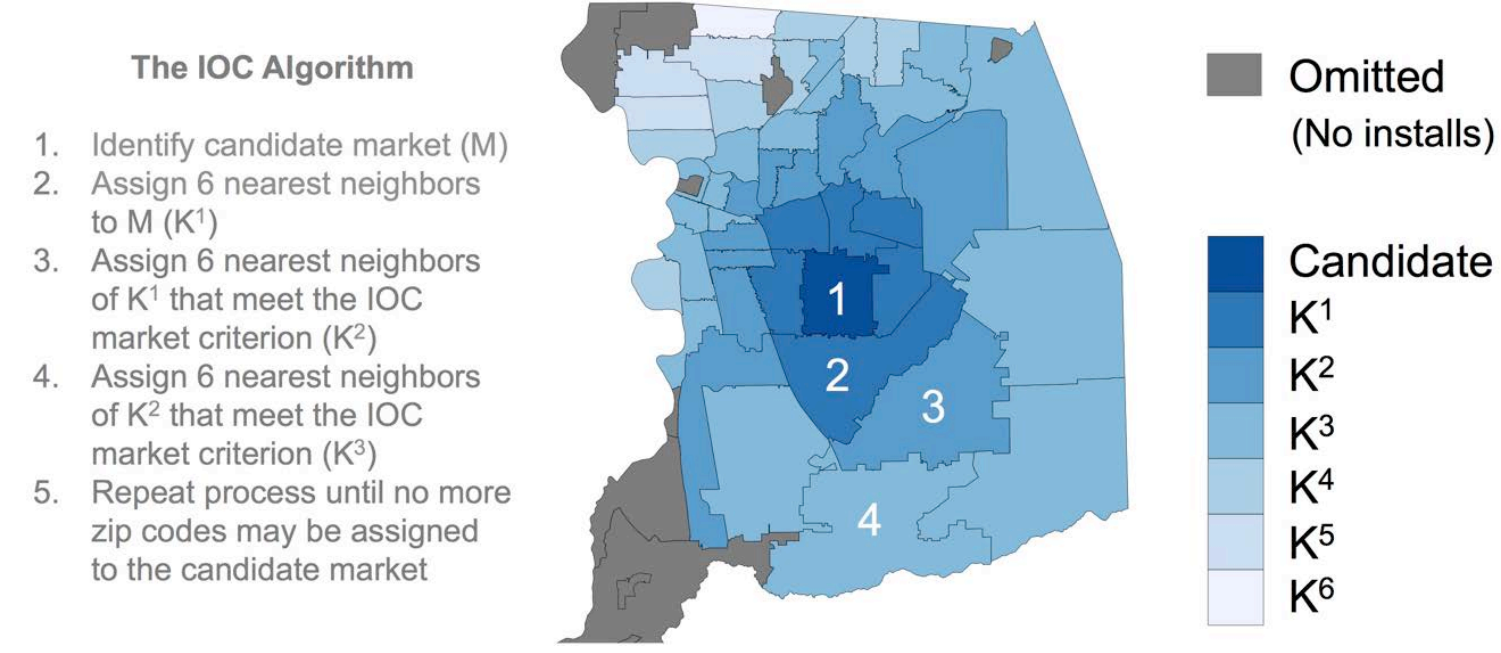

Figure 3. Visualization of the IOC algorithm in Sacramento County

Steps 1 through 3 are repeated until all zip codes are assigned to a market. Note that once a zip code is assigned to the candidate market, it is removed from the pool of eligible zip codes for market assignment, therefore all zip codes are assigned to a single market.

\footnotetext{
4 The choice of $\mathrm{k}=6$ nearest neighbors conforms to a convention in geographic analysis for the hexagonal partitioning of geographic areas. The use of hexagonal $(\mathrm{k}=6)$ rather than rectangular $(\mathrm{k}=4)$ grids can reduce edge effects and assigns equal weight to neighbors in any cardinal direction.
} 
This iterative process allows some zip codes to be isolated or "islanded" from the market definition. For example, if a zip code with many installations is adjacent to a zip code with few installations, the shared IOC may be low simply because the two zip codes differ significantly in terms of the number of systems installed, even if customers may easily substitute between installers in the adjacent zip code. As a final test for market definition performance under various approaches, we apply a spatial smoothing process to develop a third criterion $\mathbb{C}_{S}$. The $\mathbb{C}_{S}$ approach uses the $\mathbb{C}_{0.01}$ criterion as a base, then assigns all islanded zip codes to the same market as the zip code's nearest neighbor, so that the minimum market size in $\mathbb{C}_{S}$ is two zip codes.

Table 1 summarizes all three IOC market specifications.

Table 1. Summary of IOC Market Specifications

\begin{tabular}{cl}
\hline Market Specification & Definition \\
\hline $\mathbb{C}_{0.25}$ & $\mathrm{IOC}>0.25$ \\
$\mathbb{C}_{0.01}$ & $\mathrm{IOC}>0.01$ \\
& $\begin{array}{l}\text { IOC }>0.01, \text { with spatial smoother (all islanded } \\
\text { markets are assigned to market of nearest } \\
\text { neighbor) }\end{array}$ \\
\hline
\end{tabular}




\section{Results}

Given the lack of consensus around the best way to define markets, it is not surprising that there is no clear way to evaluate alternative market definitions. Importantly, market definition is in part a subjective exercise that aims to organize observed economic activity for market research purposes, so the outcomes of market definition exercises depend on the research goals (Geroski 1998). Therefore, this discussion of results is meant to demonstrate the characteristics of an installer-based approach to PV market definition, and how these characteristics may have desirable properties in certain PV market research applications. This section presents five types of results. First, we describe the properties of the IOC as a metric. Second, we describe the outcomes of the IOC algorithm in terms of market size. Third, we compare measurements of market competition under alternative market definitions. Fourth, we apply spatial statistical methods to assess the performance of the installer-based approach in explaining the spatial dependence of PV market variables. Last, we discuss how the installer-based approach improves our understanding of the spatial distribution and composition of the U.S. PV installer community.

Several of the results are presented in maps. The general convention is to display gray boundaries for zip codes with colors to indicate separate markets consisting of multiple zip codes.

\subsection{The Installer Overlap Coefficient}

The IOC as a metric illustrates the clustered spatial distribution of installers. Higher shared values of the IOC are found between closer zip codes, suggesting installer communities in any given zip code resemble installer communities in nearby areas more than installer communities in more distant areas (Figure 4). The mean IOC of a given zip code with its nearest neighbor is 0.206 , the mean IOC of any given zip code with its 10 nearest neighbor zip codes is 0.184 , while the average IOC falls to 0.118 for any given zip code and its 11 through 100 nearest neighbors. The negative relationship between the IOC and distance is a first affirmation of an installer-based market definition. The main implication is that installers in geographically distant zip codes are less likely to directly compete for the same customers and therefore less likely to exert price constraints on one another. 


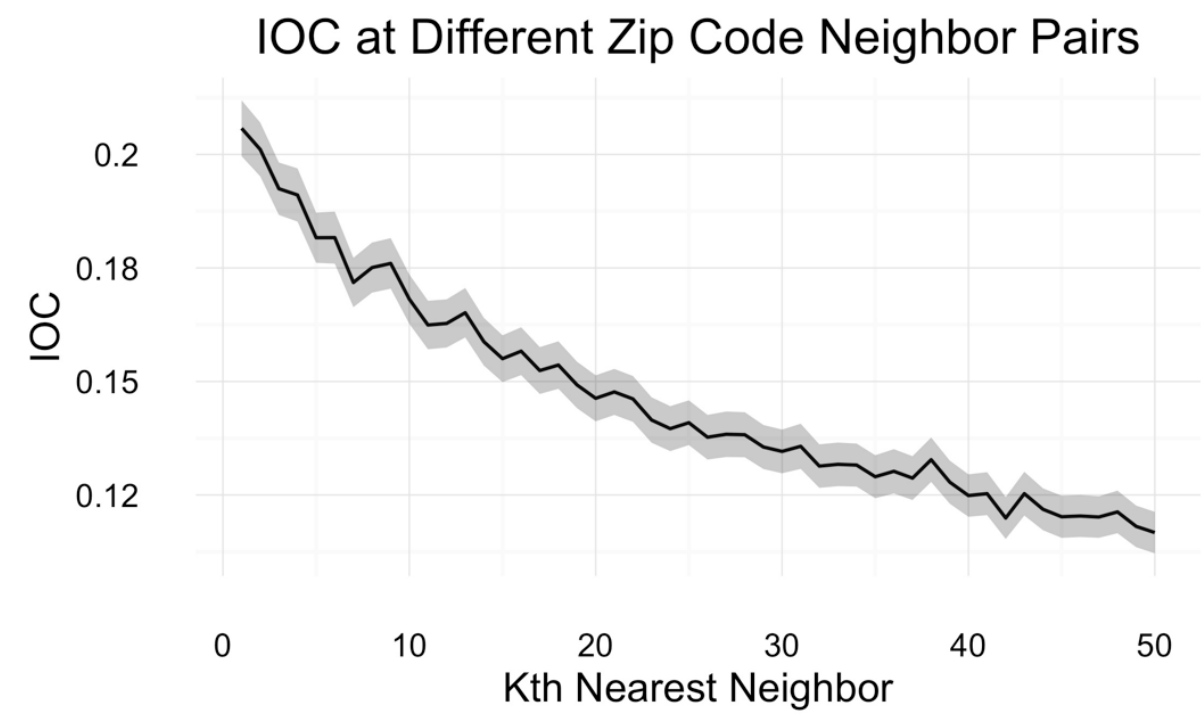

Figure 4. Mean IOC between zip codes and their $K^{\text {th }}$ nearest neighbor zip code with $95 \%$ confidence interval in gray

The IOC falls off steeply within the first 20 nearest neighbors but then begins to flatten beyond 50 neighbors. The IOC can increase at large distances. IOC values suggest that the installer communities in southern and northern California exhibit a non-trivial degree of overlap. To illustrate, the IOC of the California zip code with the most systems in the dataset (93536) is clearly highest with its neighbors in southern California (Figure 5). The IOC value then drops off to near zero in parts of central California, but then increases with zip codes in the Bay Area. The IOC reveals that similar installer communities can emerge even at large distances. 


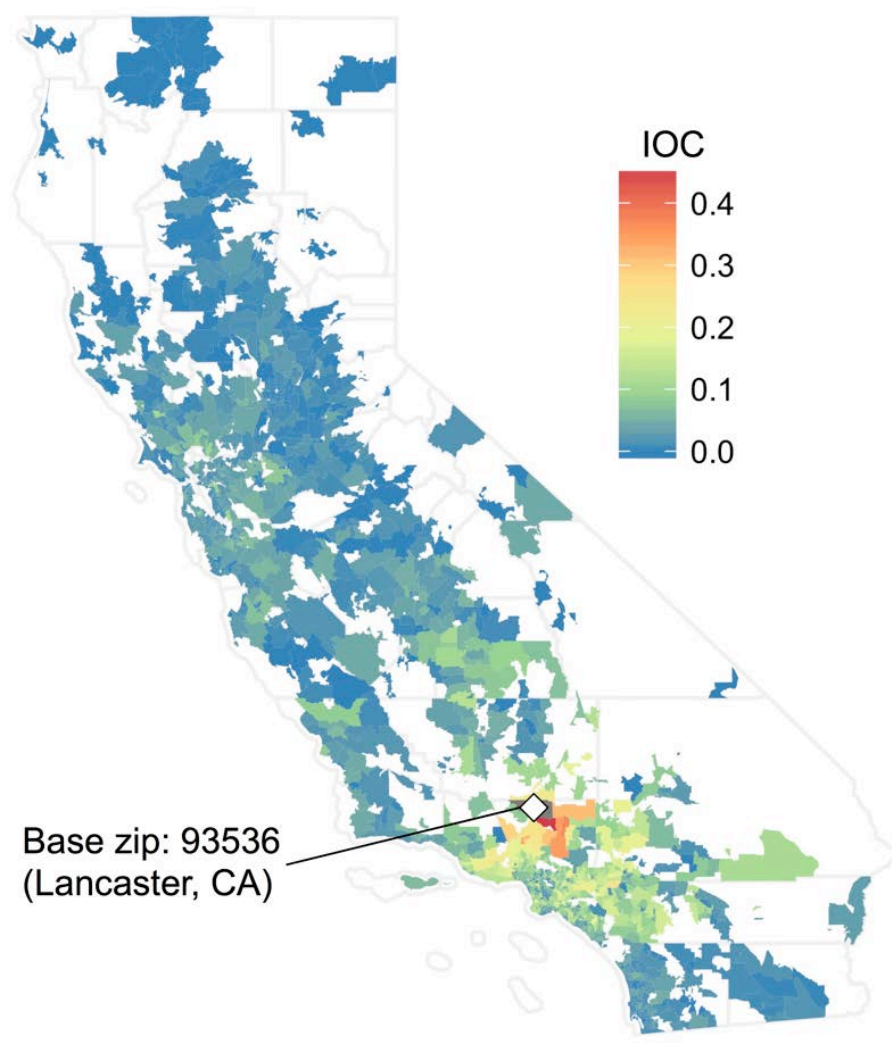

Figure 5. IOCs of California zip codes with base zip code 93536.

The highest IOC values are observed near the base zip code, but high values are also observable even at large distances, especially in the Bay Area

\subsection{Market Outcomes}

Table 2 summarizes the outcomes of the IOC algorithm applied to the data with comparisons to market definitions based on jurisdictional boundaries (county, zip). As expected, $\mathbb{C}_{0.25}$ results in the most granular outcome with 1,946 distinct markets in contrast to $\mathbb{C}_{0.01}$ with 1,759 distinct markets. The spatial smoother $\mathbb{C}_{S}$ forces 901 islanded zip codes from the $\mathbb{C}_{0.01}$ specification into neighboring markets, resulting in a significantly lower granularity with 922 distinct markets. The market granularity of these market definitions falls between a zip code level definition $(n=6,103)$ and a county-level definition $(n=535)$ (Figure 6).

Table 2. PV Market Definition Outcomes

\begin{tabular}{lccccc}
\hline & County & Zip & $\mathbb{C}_{\mathbf{0 . 2 5}}$ & $\mathbb{C}_{\mathbf{0 . 0 1}}$ & $\mathbb{C}_{\boldsymbol{S}}$ \\
\hline \# of markets & 535 & 6,103 & 1,946 & 1,759 & 922 \\
Mean IOC & 0.150 & 0.206 & 0.175 & 0.160 & 0.156 \\
Mean \# of zip codes & 11.4 & 1 & 3.14 & 3.47 & 6.6 \\
Mean \# of systems & 251 & 22.0 & 68.9 & 76.2 & 145.4 \\
\hline
\end{tabular}

The mean IOC between all zip codes in the data is 0.023 , so the significantly higher mean IOCs observed in all three IOC approaches and the county-level market definition suggest that these 
market definitions identify unique installer clusters. The $\mathbb{C}_{0.25}$ specification maximizes the mean IOC, while the spatial smoothing in $\mathbb{C}_{S}$ comes with the cost of a lower mean IOC, that is, relatively lower installer overlap within the market boundaries.

The effects of changing the value of $\mathbb{C}$ varied slightly by region. There were about 11.9 and 10.6 $\mathbb{C}_{0.25}$ defined markets per county in eastern Massachusetts and New Jersey, while about 15.7 $\mathbb{C}_{0.25}$ markets per county in the Phoenix Area (Figure 7). The spatial smoother $\mathbb{C}_{S}$ falls about halfway between the most granular IOC definition and a county market definition across different regions. Regional differences are driven by differences in local installer compositions, a theme we explore further in the conclusion. 


\section{Market Boundaries for the Bay Area, CA}

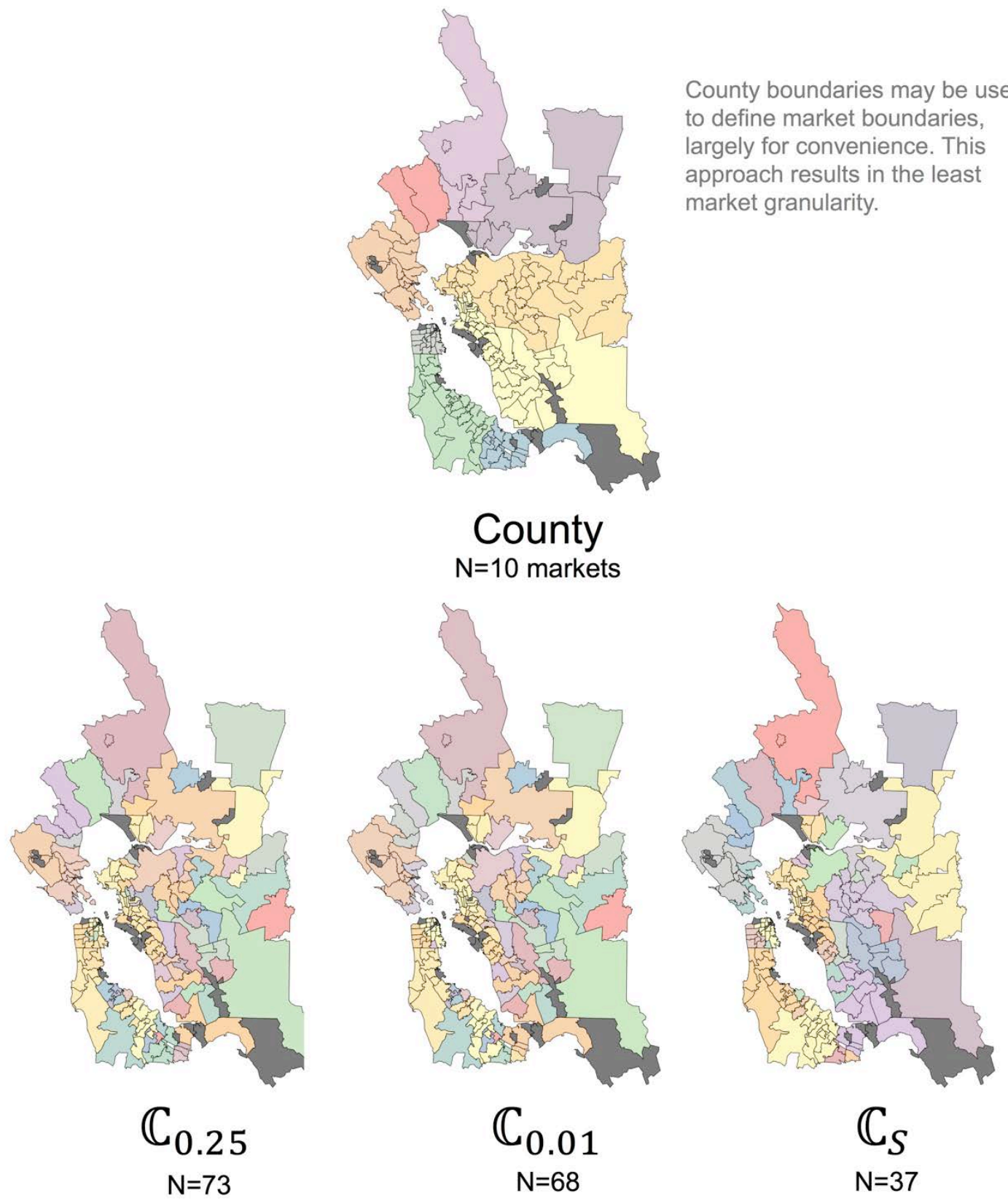

The IOC approaches all increase market granularity relative to a county market definition. The $I O C=0.25$ specification requires the highest degree of installer overlap and therefore results in more market segregation than the other specifications. The $\mathrm{IOC}=0.01$ requires less installer overlap, and the spatial smoother $\mathrm{S}$ more closely resembles a county market definition while still maintaining higher resolution.

Figure 6. Market boundaries by county and under different IOC thresholds.

Note: Color scheme is non-continuous, color shades do not correspond to different values, but are rather used to distinguish neighboring markets. Dark gray areas represent omitted zip codes (no systems). All gray boundaries represent zip codes. 


\section{County}

Eastern Massachusetts

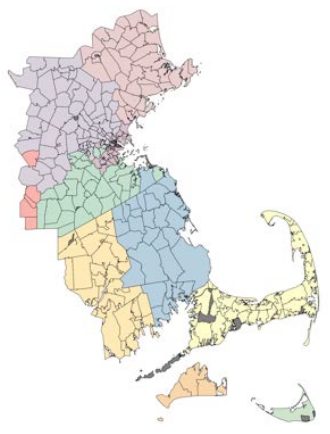

$\mathrm{N}=11$

Northern New Jersey

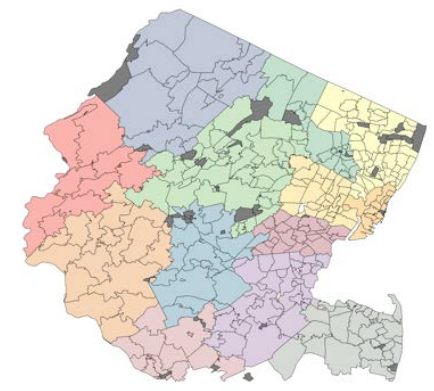

$\mathrm{N}=14$

Greater Phoenix Area

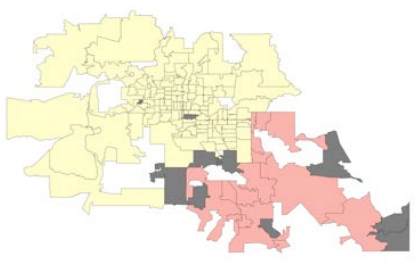

$\mathrm{N}=3$
$\mathbb{C}_{0.25}$

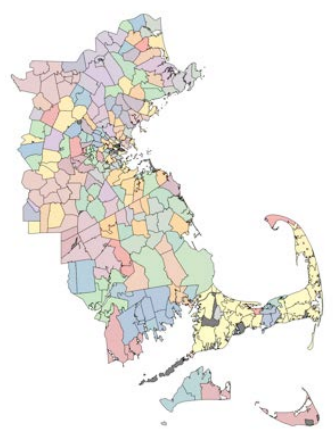

$N=131$

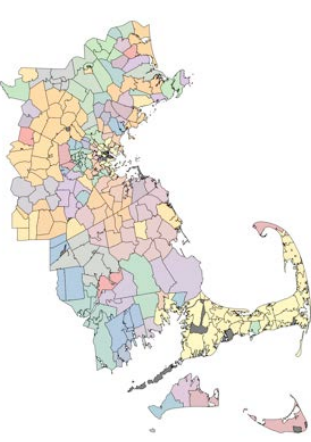

$\mathrm{N}=84$

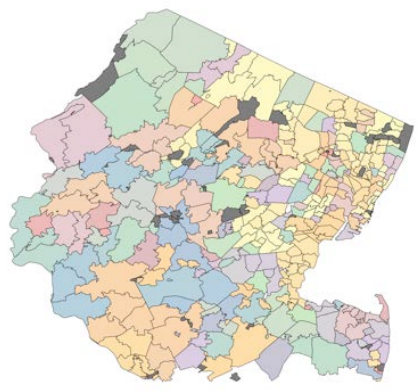

$\mathrm{N}=149$

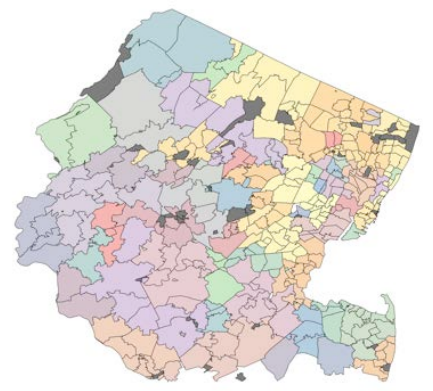

$\mathrm{N}=72$

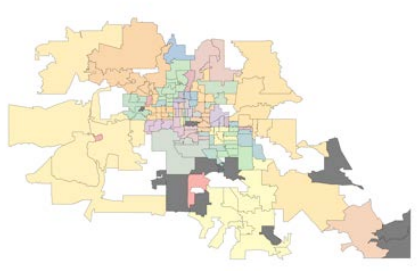

$\mathrm{N}=47$

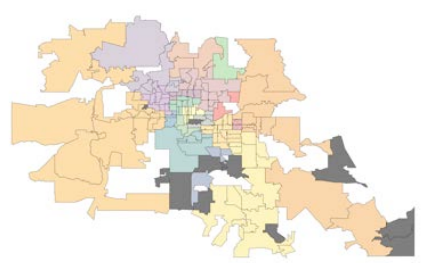

$\mathrm{N}=20$

Figure 7. Illustrations of market outcomes for three example regions.

Dark gray areas correspond to omitted zip codes (no systems).

\subsection{Measures of Competition under Market Outcomes}

Market competition metrics are sensitive to the approach used to define market boundaries. PV market research at the county level may miss local nuances that result from installer clustering below the county level. To illustrate, consider two installers X and Y in Los Angeles County (Figure 8). ${ }^{5}$ The two installers have comparable market shares when measured at the county

\footnotetext{
${ }^{5}$ Installers " $\mathrm{X}$ " and "Y" are based on actual data.
} 
level. However, installer X holds a stronger share in southwestern Los Angeles County, while installer Y holds a stronger share in southeastern Los Angeles County. Market analyses that control for installer market share at the county level would underestimate installer Y's market share in southeastern Los Angeles County by a factor of about three. Figure 8 clearly demonstrates the advantage of the IOC approach, which may allow researchers to make more precise inferences about installer local market shares and assess the role of local market dynamics on pricing. Through the IOC approach, future research could assess the behavior of installers $\mathrm{X}$ and $\mathrm{Y}$ in their respective market niches, rather than assuming that the county-level market share roughly approximates local market shares.

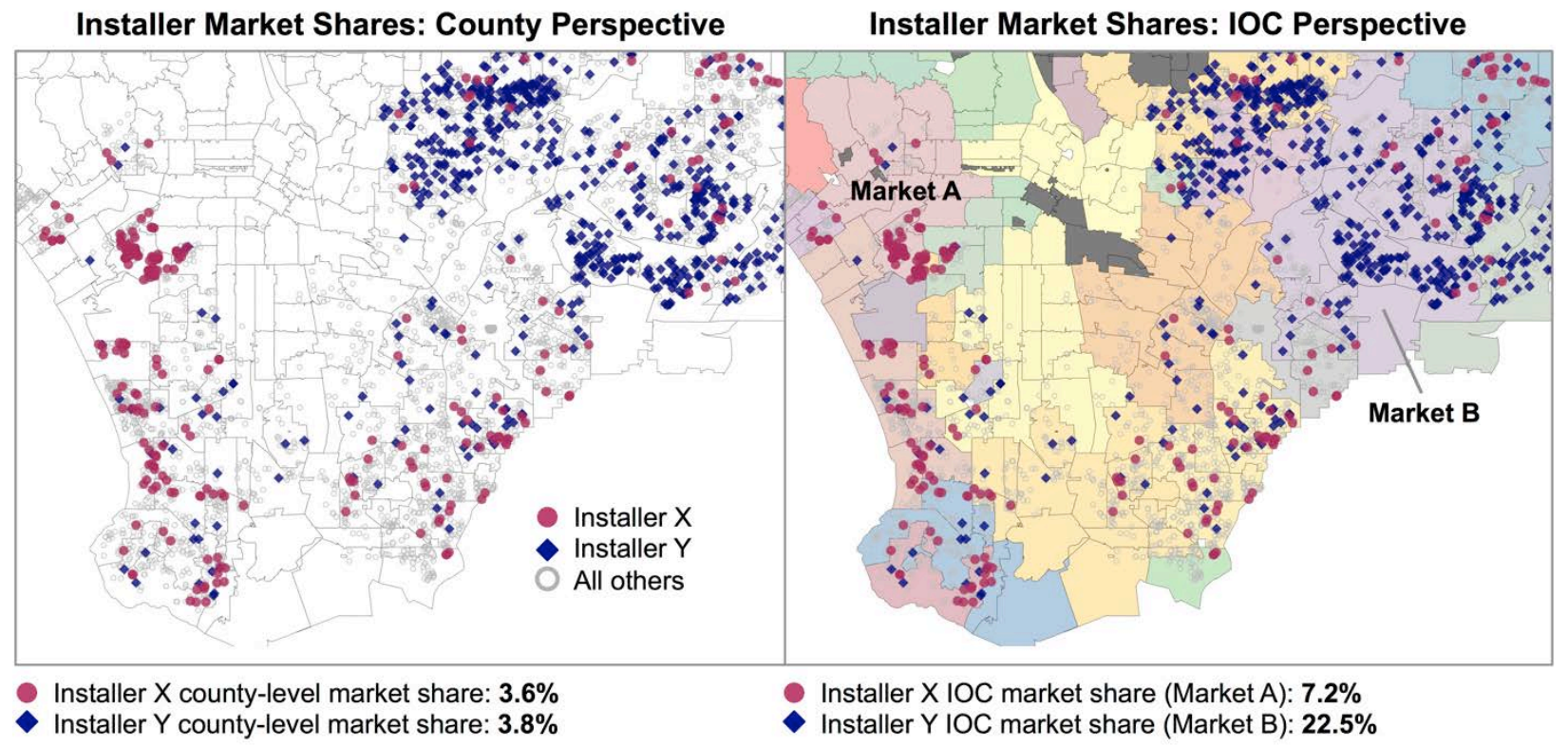

Figure 8. Visualization of installer market share measured at the county level (left panel) and IOC market level (right panel)

The patterns of installer market share clustering in Figure 8 appear to be the rule rather than the exception. Figure 9 compares local market shares (based on the $\mathbb{C}_{S}$ specification) in Los Angeles County with county-level market shares for four example installers. ${ }^{6}$ All four installers exhibit clear clustering with stronger market share in certain pockets of the county (right tails) and weaker market share in other parts of the county (left tails). In contrast to a county-level approach, the IOC approach could allow future research to analyze differences in installer behavior based on their local market share. Further, the IOC approach may allow researchers to assess why some installers exhibit more market share clustering than others. For example, both installers 2 and 3 show significantly high market shares in a single market, while installer 4 holds relatively more balanced market shares throughout Los Angeles County.

6 Installers 1-4 are based on actual data. 


\section{Local Market Shares ( $\mathrm{N}=38 \mathrm{IOC}$ markets) Compared to County-Level Shares for Four Example Installers in Los Angeles County}
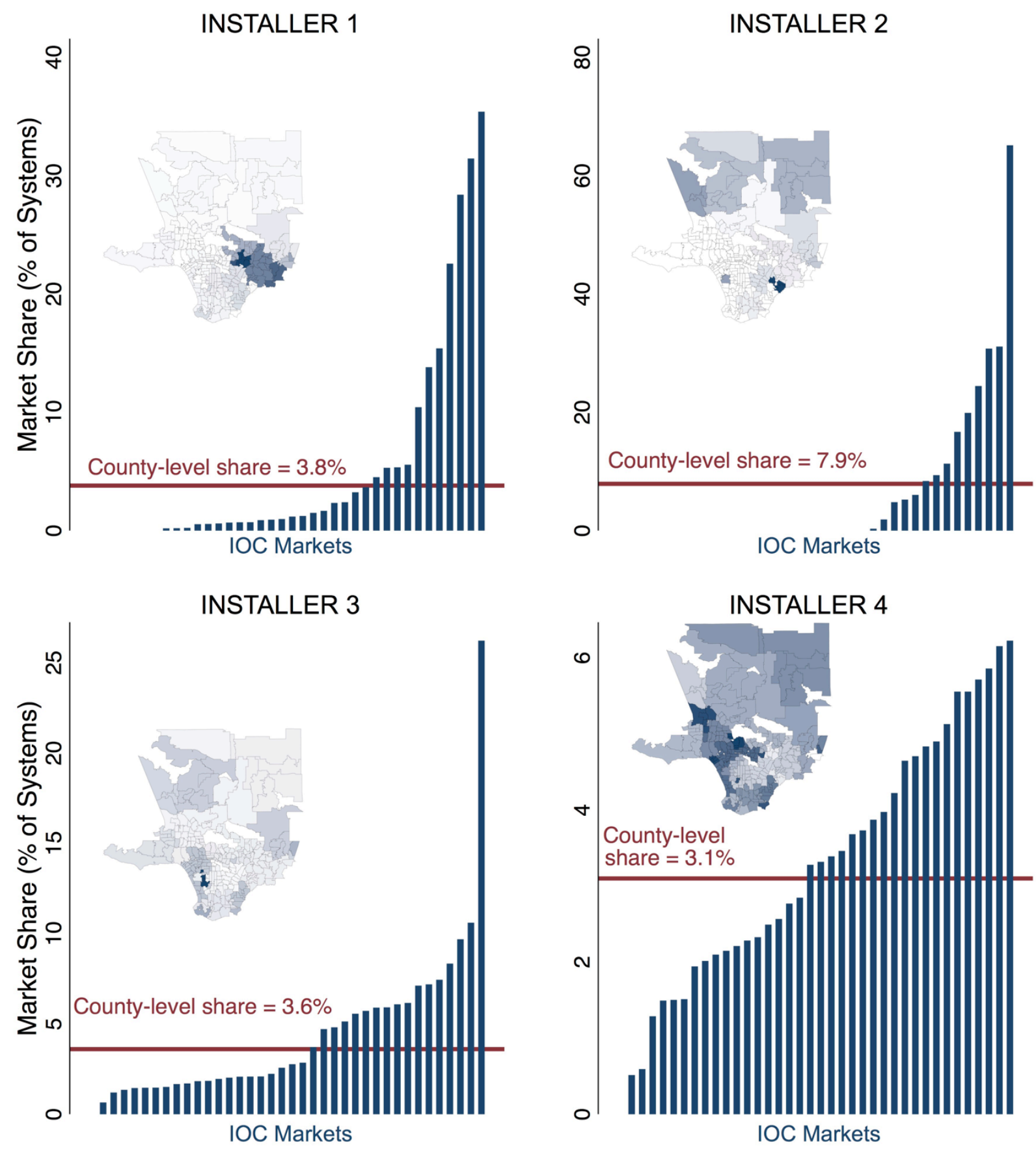

Figure 9. Local market shares $\left(\mathbb{C}_{S}\right.$ specification) compared to county-level market shares for four example installers in Los Angeles County.

Note that all maps and charts are on separate scales for each installer. 
The Herfindahl-Hirschman Index (HHI) is a commonly used metric for the level of competition in a market. The HHI is calculated as the squared sum of market shares of all firms in a given market:

$$
H H I=\sum_{i=1}^{N} m s_{i}^{2}
$$

Where $m s_{i}^{2}$ is the squared market share (\%) of firm $i$ of $N$ firms in a given market. A higher HHI indicates that a small number of firms hold large market shares and suggests a less competitive market. For the purposes of this analysis, we define market share as an installer's share of all systems in a given market between 2013 and 2014. The Department of Justice uses HHI thresholds for defining markets as moderately $(>0.15)$ and highly $(>0.25)$ concentrated.

HHI correlation coefficients between a county-level definition and the IOC market definitions range from $0.40\left(\mathbb{C}_{0.01}\right.$ and $\left.\mathbb{C}_{0.25}\right)$ to $0.54\left(\mathbb{C}_{S}\right)$. Thus, the $\mathbb{C}_{S}$ specification (lowest market granularity) is most closely correlated with the county-level definition. The distribution of HHI outcomes for the IOC approach under the $\mathbb{C}_{0.25}$ and $\mathbb{C}_{0.01}$ specifications are similar to countylevel HHIs (Figure 10). The average HHI for county, $\mathbb{C}_{0.25}$, and $\mathbb{C}_{0.01}$ market definitions were $0.43,0.39$, and 0.41 , respectively. These three market definitions have bimodal distributions with large numbers of markets with HHIs between 0.2 and 0.4 and large numbers of markets with HHIs approaching 1 . In contrast, the HHI distribution in the $\mathbb{C}_{S}$ specification deviates significantly from both the county market definition and the other IOC approaches. This deviation is partly due to the function of the spatial smoother in $\mathbb{C}_{S}$, which requires a minimum market size of two zip codes and therefore two systems. In contrast, the other market specifications have a large number of isolated markets with single systems, where the $\mathrm{HHI}$ is 1 by definition. More than $80 \%$ of markets (in all specifications) with an $\mathrm{HHI}$ equal to one had only a single system.

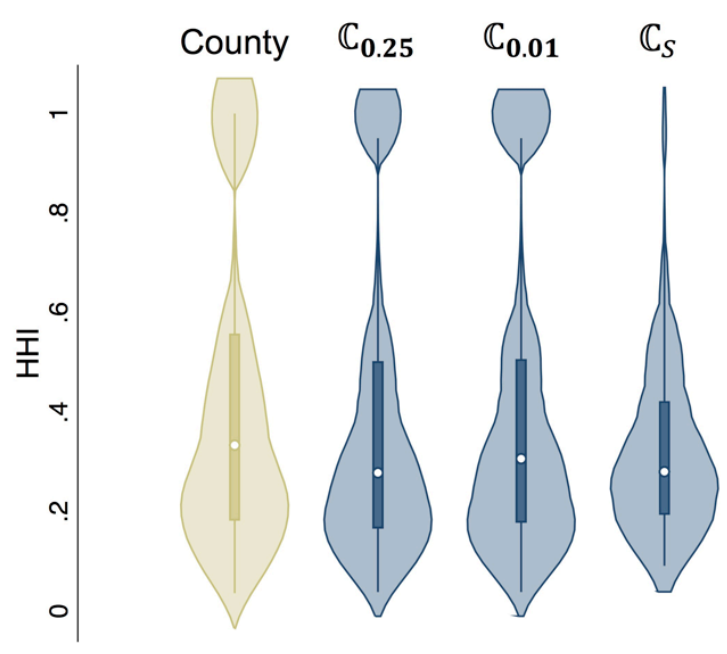

Figure 10. Distributions of HHI under different market definitions 


\subsection{Evaluative Statistics}

One possible measure of the performance of alternative PV market definitions is how well they capture spatial relationships. Well-defined markets may group zip codes that share similar market characteristics in terms of metrics such as install price and installer density. In spatial statistics, the interaction between values of one metric in one location and the values of the same metric in neighboring locations is known as spatial dependence or spatial autocorrelation. Moran's $I$ test is the most commonly used specification for spatial dependence (Anselin 2001). Moran's I measures the relationship between a variable and a spatial lag representing the weighted average value of the variable at neighboring locations (Anselin 2001; Bivand et al. 2013). Neighbor relationships are represented in an $\mathrm{N} \times \mathrm{N}$ spatial weights matrix $\mathrm{W}$ where each value $w_{i j}$ represents the degree to which areas $i$ and $j$ are spatially linked. We follow the standard approach of row-standardizing $\mathrm{W}$ such that the sum of reach row $\sum_{j} w_{i j}=1$ (Anselin 2001). Formally, Moran's $I$ is given:

$$
I=\frac{n \sum_{i=1}^{n} \sum_{j=1}^{n} w_{i j}\left(y_{i}-\bar{y}\right)\left(y_{j}-\bar{y}\right)}{\left(\sum_{i=1}^{n} \sum_{j=1}^{n} w_{i j}\right) \sum_{i=1}^{n}\left(y_{i}-\bar{y}\right)^{2}}
$$

Where $y_{i}$ is the $i^{t h}$ observation of a given variable of interest $y, \bar{y}$ is the mean of the variable of interest, and $w_{i j}$ is the $i^{\text {th }}$ row of the $j^{\text {th }}$ column in the spatial weights matrix W. Moran's $I$ effectively centers observations of the variable of interest $\left(y_{i}\right)$ around on a constant mean $(\bar{y})$, then asserts that any remaining relationships are explained by spatial dependence (Bivand et al. 2013).

We test for spatial dependence under alternative market definitions for installer density (number of installers per zip code) and mean install prices $(\$ / \mathrm{W})$ using Moran's $I$ with five binary spatial weighting specifications (Table 3 ). ${ }^{7}$ The three spatial weight matrices $\mathrm{W}_{\mathrm{C} 25}, \mathrm{~W}_{\mathrm{C} 01}$ and $\mathrm{W}_{\mathrm{CS}}$ test the spatial dependence of zip codes within the IOC defined markets. The results of these tests are compared with two counterfactuals. First, the specification $\mathrm{W}_{\mathrm{nn}}$ tests the spatial dependence of zip codes with their nearest neighbor zip code. This specification represents a purely geographically defined approach that should theoretically be the strongest representation of true spatial dependence. However, such an approach is not tenable for market definition given that $\mathrm{W}_{\mathrm{nn}}$ is asymmetric, i.e., the relevant market depends on the zip code in question. The second counterfactual is a jurisdictionally defined spatial weights matrix $\mathrm{W}_{\mathrm{CTY}}$, where markets are defined by county boundaries.

${ }^{7}$ All Moran's I tests were operationalized in R using the spdep and ape packages (Bivand and Piras 2015; Paradis et al. 2004). 
Table 3. Spatial Weights Matrices Definitions for Moran's I Tests

\begin{tabular}{ll}
\hline $\begin{array}{l}\text { Spatial Weights } \\
\text { Matrix }\end{array}$ & Description \\
\hline$W_{\mathrm{nn}}$ & $\begin{array}{l}\mathrm{W}_{\mathrm{ij}} \text { takes on a value of } 1 \text { if zip code } j \text { is the nearest } \\
\text { neighbor of zip code } i \text {, and a } 0 \text { if otherwise }\end{array}$ \\
$\mathrm{W}_{\mathrm{CTY}}$ & $\begin{array}{l}\mathrm{W}_{\mathrm{ij}} \text { takes on a value of } 1 \text { if zip codes } i \text { and } j \text { are located in } \\
\text { the same county, and a } 0 \text { if otherwise }\end{array}$ \\
$W_{\mathrm{C} 25}$ & $\begin{array}{l}\mathrm{W}_{\mathrm{ij}} \text { takes on a value of } 1 \text { if zip codes } i \text { and } j \text { are located in } \\
\text { the same } \mathbb{C}_{0.25} \text { market, and a } 0 \text { if otherwise }\end{array}$ \\
$\mathrm{W}_{\mathrm{C} 01}$ & $\begin{array}{l}\mathrm{W}_{\mathrm{ij}} \text { takes on a value of } 1 \text { if zip codes } i \text { and } j \text { are located in } \\
\text { the same } \mathbb{C}_{0.01} \text { market, and a } 0 \text { if otherwise }\end{array}$ \\
$W_{\mathrm{CS}}$ & $\begin{array}{l}\mathrm{W}_{\mathrm{ij}} \text { takes on a value of } 1 \text { if zip codes } i \text { and } j \text { are located in } \\
\text { the same } \mathbb{C}_{S} \text { market, and a } 0 \text { if otherwise }\end{array}$ \\
\hline
\end{tabular}

There are three important methodological limitations to note before proceeding to the results. First, Moran's $I$ is sensitive to the sum of the spatial weights matrix W. Row standardization should partially alleviate this issue. However, in some market definitions certain zip codes have no neighbors and are effectively dropped from the analysis, reducing the sum of $\mathrm{W}$ and thus the magnitude of Moran's $I$. This may particularly affect the analysis for $\mathrm{W}_{\mathrm{C} 25}$ and $\mathrm{W}_{\mathrm{C} 01}$, where some zip codes were "islanded" during the IOC algorithm process. Second, Moran's I may be biased if observations are spatially correlated due to non-spatial factors. For example, local solar PV policies may influence prices such that prices are locally correlated not because of their proximity but because of the common policy environment. This issue could theoretically be resolved by conditioning the variables of interest on other spatial variables (e.g., local solar policies) in the Moran's I tests. However, the influence of local policies and other localized factors on solar PV markets is not yet well understood (Nemet et al. 2016). We therefore opt for the simplicity of using prices and installer density, with the caveat that the Moran's $I$ in this case is essentially a simplified model used for illustrative purposes to compare the extent of spatial dependence under different market definitions. Third, a pitfall in the use of zip codes as our geographic unit of analysis is that distances between zip codes can vary significantly. A practical solution to this problem is to further adjust the spatial weights matrices through inverse distance weighting, which assigns greater weights to relationships between close neighbors than distant neighbors.

The Moran's I results suggest strong spatial dependence in both installer density and installed system prices under all five market definitions (Table 4). The Z statistics in Table 4 are a function of the variance of $I$ and therefore are, in general, positively correlated with the number of neighbor pairs. Definitions with few neighbor pairs $\left(\mathrm{W}_{\mathrm{nn}}\right)$ will generally have lower $\mathrm{Z}$ statistics while definitions with many neighbor pairs $\left(\mathrm{W}_{\mathrm{CTY}}\right)$ will generally have higher $\mathrm{Z}$ statistics. The magnitude of spatial dependence in all three IOC specifications is generally comparable to spatial dependence at the county level. 
Table 4. Moran's I Test Results (Z statistics in parentheses)

\begin{tabular}{lccccc}
\hline & $\mathbf{W}_{\mathrm{nn}}$ & $\mathbf{W}_{\mathbf{C T Y}}$ & $\mathbf{W}_{\mathbf{C 2 5}}$ & $\mathbf{W}_{\mathbf{C 0 1}}$ & $\mathbf{W}_{\mathrm{CS}}$ \\
\hline Install price & 0.30 & 0.25 & 0.25 & 0.25 & 0.24 \\
& $(19.2)$ & $(45.6)$ & $(23.8)$ & $(26.0)$ & $(28.8)$ \\
Installer density & 0.60 & 0.51 & 0.50 & 0.47 & 0.49 \\
& $(37.7)$ & $(92.1)$ & $(47.2)$ & $(49.9)$ & $(58.7)$ \\
\hline Neighbor pairs & 6,103 & 233,428 & 27,584 & 40,592 & 53,168 \\
\hline
\end{tabular}

The magnitude of spatial dependence is generally slightly higher in the IOC specifications than at the county-level when local relationships are weighted more heavily than distant relationships (Table 5). One interpretation is that the IOC approach captures more highly local spatial dependence while the county-level approach captures more large-scale spatial dependence (e.g., state-level policy differences).

Table 5. Moran's I Test Results with Inverse Distance Weighting (Z statistics in parentheses)

\begin{tabular}{lccccc}
\hline & $\mathbf{W}_{\mathrm{nn}}$ & $\mathbf{W}_{\mathbf{C T Y}}$ & $\mathbf{W}_{\mathbf{C 2 5}}$ & $\mathbf{W}_{\mathbf{C 0 1}}$ & $\mathbf{W}_{\mathbf{C S}}$ \\
\hline Install price & 0.30 & 0.27 & 0.29 & 0.28 & 0.27 \\
& $(19.2)$ & $(38.3)$ & $(23.3)$ & $(24.6)$ & $(26.8)$ \\
Installer density & 0.60 & 0.52 & 0.54 & 0.53 & 0.55 \\
& $(37.7)$ & $(74.1)$ & $(43.7)$ & $(46.8)$ & $(54.7)$ \\
\hline Neighbor pairs & 6,103 & 233,428 & 27,584 & 40,592 & 53,168 \\
\hline
\end{tabular}

The Moran's I results may be visualized through Moran plots. A Moran plot displays observed values for a given variable (x-axis) with the mean value of the given variable at neighboring locations (y-axis), i.e., the spatial lag of the variable. The linear relationship in the Moran plot depicts Moran's I. The Moran's plots for prices show that the IOC markets exhibit similar magnitudes of spatial price dependence as $\left(\mathrm{W}_{\mathrm{nn}}\right)$ and counties $\left(\mathrm{W}_{\mathrm{CTY}}\right)$ (Figure 11). The interpretation is that installed system prices in any given zip code are strongly influenced by system prices in other zip codes in the same IOC market. 

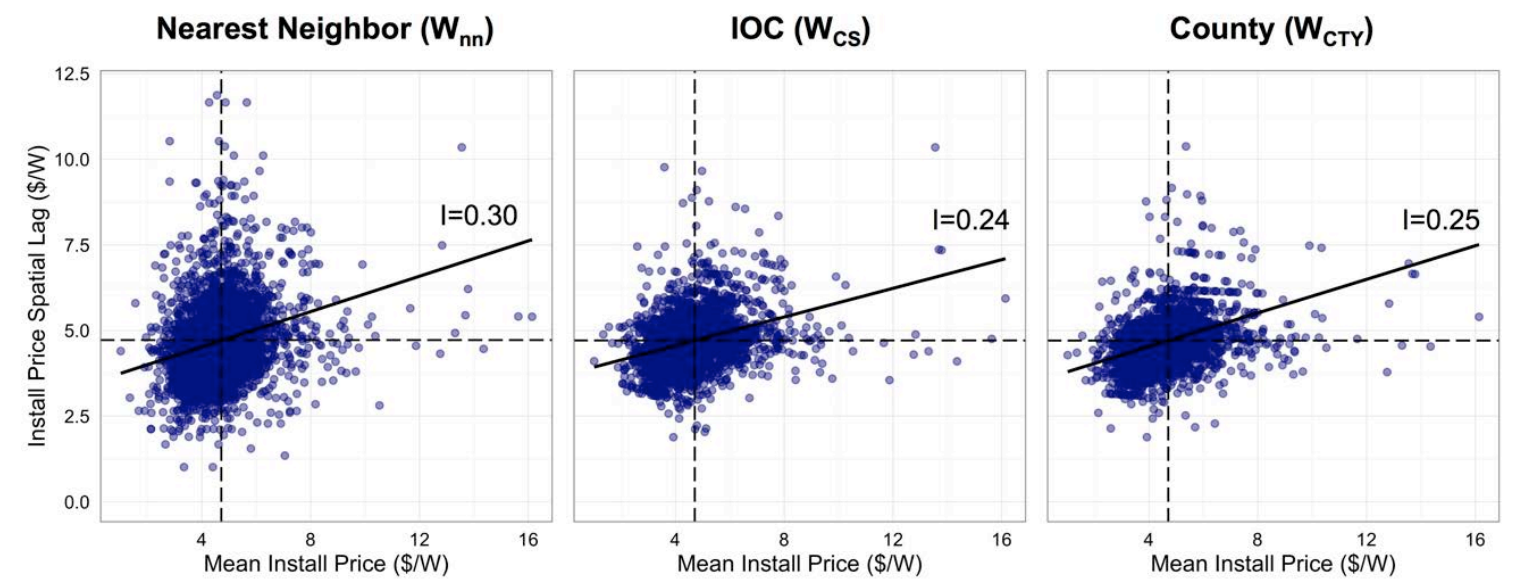

Figure 11. Moran scatterplots for spatially lagged install prices.

The trend line represents Moran's I, the dashed lines correspond to the mean install price ( $\mathrm{x}$-axis) and mean install price spatial lag (y-axis). For ease of interpretation, the figure is based on spatial weights without inverse distance weighting.

The shortcomings of the county-level approach are more readily apparent in the Moran scatterplot in Figure 12. A county-level market definition arbitrarily assigns heterogeneous regions into a jurisdiction-defined market regardless of the dissimilarity of the zip codes. The nearly straight horizontal lines of points in the county specification of Figure 12 reflect zip codes with heterogeneous installer densities coerced into a single county-level market. In contrast, the IOC was calibrated according to installer compositions and thus splits markets where the installer composition of one zip code ceases to reflect the installer composition of neighboring zip codes. As a result, we see stronger granularity in the IOC Moran plot (Figure 12).
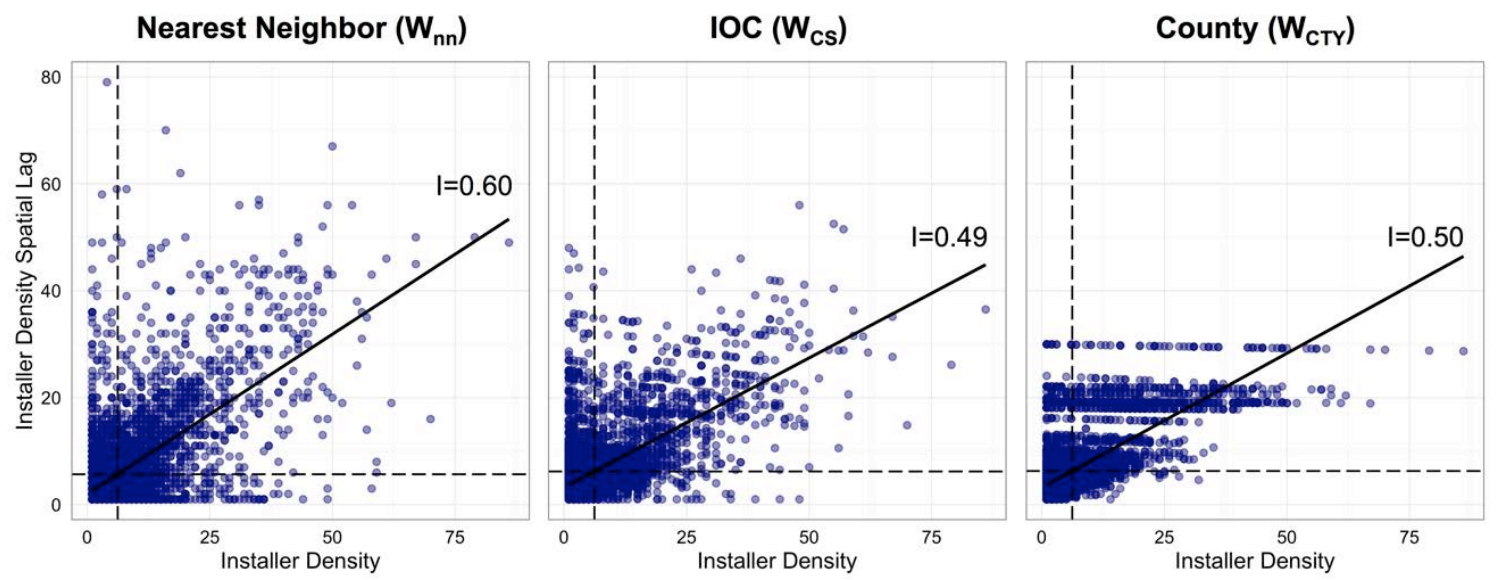

Figure 12. Moran scatterplots for spatially lagged installer density.

The trend line represents Moran's I, the dashed lines correspond to the mean installer density (x-axis) and mean installer density spatial lag (y-axis). For ease of interpretation, the figure is based on spatial weights without inverse distance weighting.

The Moran plot in Figure 12 suggests that a county-level market definition may be too large, forcing fundamentally dissimilar local markets into broad county boundaries. Returning to the methodological foundation, the implication is that some installers within county-defined markets 
may exert only minor price constraints on other installers within the same market, which could undermine PV market research based on the county-level market definition. We calculate a Moran's I correlogram for installed prices and installer density to test the appropriateness of different market sizes. The Moran's I correlogram calculates the Moran's I statistic between two points at different distances from each other or, in this case, the Moran's I for increasingly distant neighbor pairs. The Moran's I statistic for a spatially autocorrelated process should generally decline as the distance between two points increases. This relationship is evident for both install prices and installer density (Figure 13). The average Moran's $I$ for install prices between a zip code and its 10 nearest neighbors is about 0.23 , compared to about 0.18 between a zip code and its $11^{\text {th }}$ through $50^{\text {th }}$ nearest neighbors $(t=5.2)$. Similarly, the average Moran's $I$ for installer density is 0.61 within 10 neighbors, and 0.52 for the $11^{\text {th }}$ to $50^{\text {th }}$ nearest neighbors $(t=10.9)$. These results support our methodological premise that the mutual competitive pressures of installers may be inferred from their spatial distribution, given that the spatial dependence of market-level metrics becomes weaker for increasingly distant zip codes.
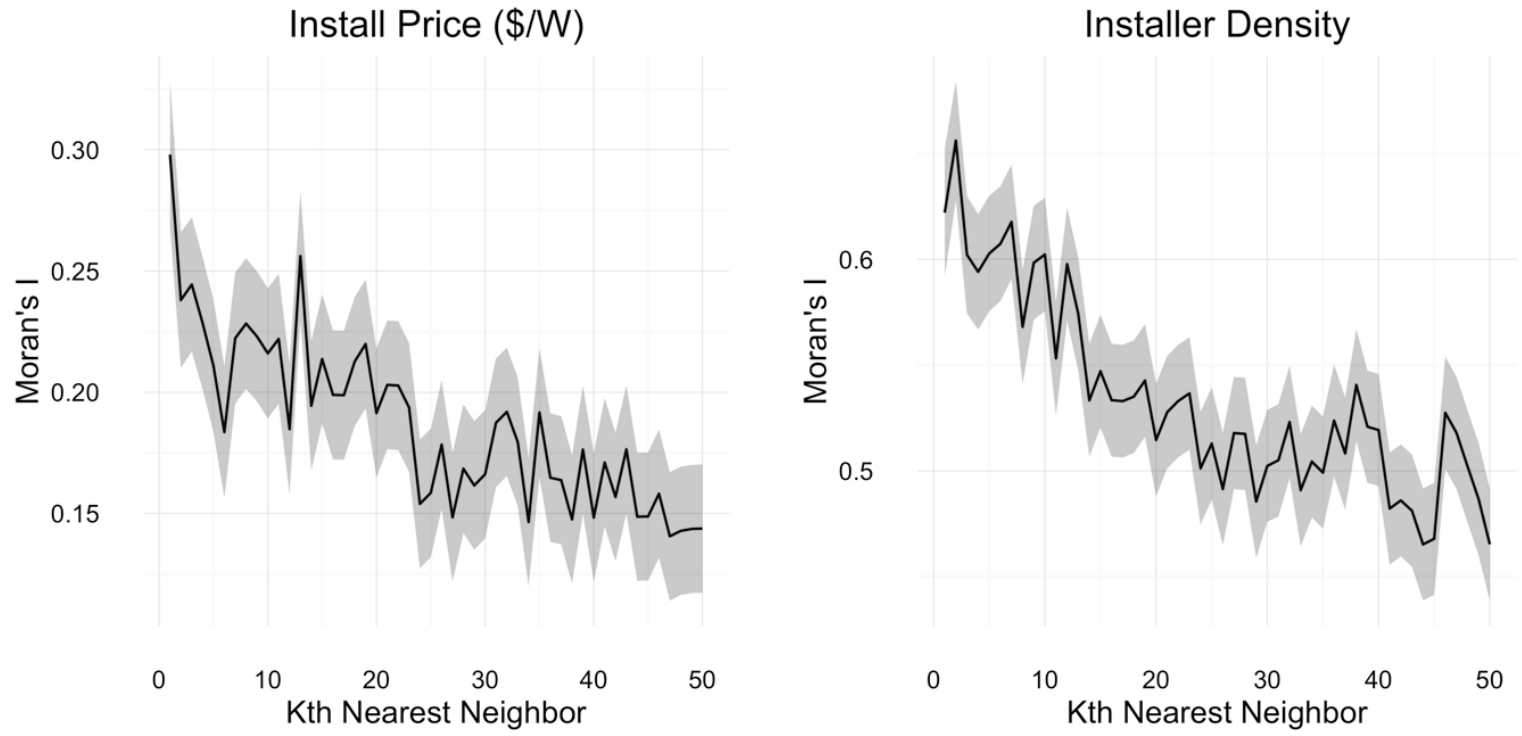

Figure 13. Moran's I spatial correlograms for install prices (left panel) and installer density (right panel) with $95 \%$ confidence intervals in gray

The $\mathrm{x}$-axis corresponds to the Kth nearest neighbor of any given zip code. Plots are not on same scale.

The results of the spatial correlograms further support the strength of the IOC approach relative to the use of county boundaries for PV market definition. About $50 \%$ of zip codes in countydefined markets are beyond the $10^{\text {th }}$ neighbor of some other zip code within the county, compared to about $12 \%$ of zip codes in the IOC approach $\left(\mathbb{C}_{s}\right)$. This suggests that about half of zip codes in county-defined markets are arbitrarily grouped into market boundaries with other zip codes between which there is relatively low spatial dependence. Nonetheless, it should be noted that spatial dependence in both install prices and installer density is still statistically significant even out to the $50^{\text {th }}$ nearest neighbor. This suggests that broad factors of spatial influences contribute to the spatial autocorrelation of PV market variables even at large geographic scales. 


\subsection{Using the IOC to Understand the Spatial Distribution of Installers}

The outcome of the IOC algorithm is also essential in the understanding of the heterogeneous spatial distribution of the U.S. PV installer community. The key premise of this installer-based approach is that the degree to which installers exert price constraints on one another may be inferred from their spatial distribution. The outcomes of the IOC algorithm are therefore dictated by the spatial distributions of a heterogeneous mix of small- and large-scale installers. Specifically, two competing dynamics drive the IOC outcome: the market integration pressures of large, national-scale installers and the market segregation pressures of small, local-scale installers. These dynamics can be observed through the relationship between installer diversity and IOC market sizes. Installer diversity can be measured by the ratio of unique installers to the number of systems in the market, where a high value of installers/installs indicates a relatively diverse installer community. IOC market size is negatively correlated with installer diversity (Figure 14). In general, there were about 0.3 more installers per install in markets comprised of fewer than 10 zip codes than in larger markets $(t=15.5)$, based on the $\mathbb{C}_{S}$ specification. This relationship is intuitive given the calibration of the IOC algorithm. In an extreme case, the IOC algorithm would converge toward a single national market if large, national-scale installers were to gain increasing market share throughout the United States (lower installer diversity).

Alternatively, the IOC algorithm would converge toward complete market disaggregation if small, local-scale installers were to gain increasing market share (higher installer diversity).

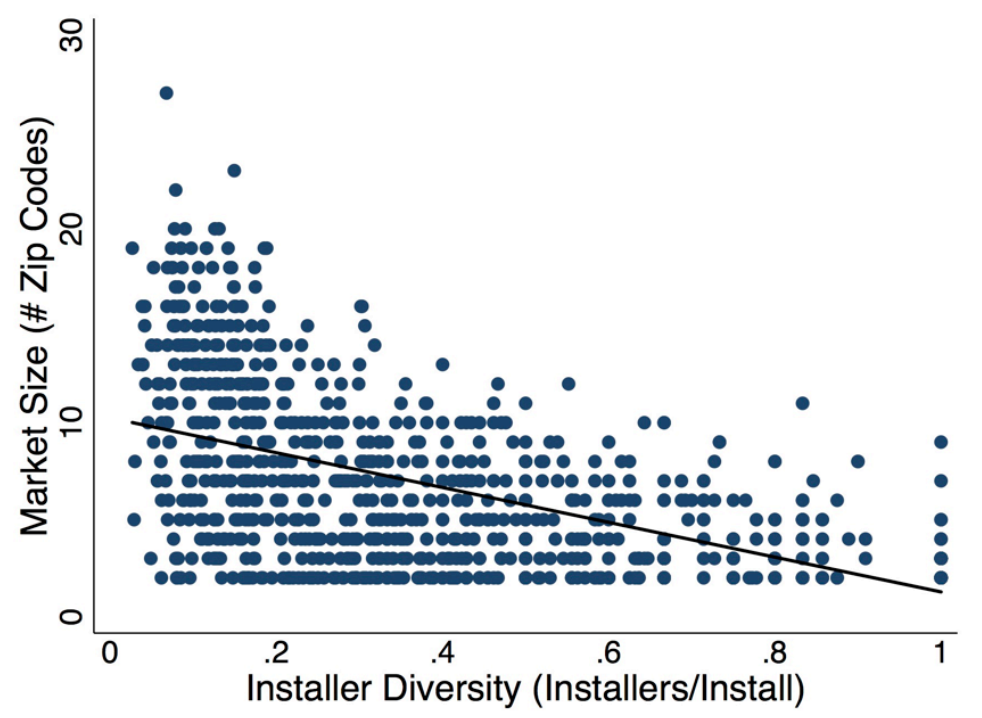

Figure 14. Market size as a function of installer diversity ( $\mathbb{C}_{S}$ specification)

The IOC approach resulted in far smaller market sizes on average than a county-level market definition, which illustrates the influence of small-scale installers. The IOC algorithm reveals a U.S. solar PV market akin to an environment where local ecosystems are both differentiated by endemic species (local installers) and assimilated by ubiquitous species (national installers). Under the $\mathbb{C}_{s}$ market specification, about $85 \%$ of installers operated in fewer than 10 markets (local installers), while about $0.5 \%$ of installers can be found in more than 100 markets in multiple states (national-scale installers). Local installers account for about $12 \%$ of systems, while national-scale installers account for about $53 \%$ of systems. Importantly, the market areas of local- and national-scale installers are not mutually exclusive; rather the two groups of 
installers compete for the same customers at local scales in some of the strongest PV markets (Figure 15). In other words, clusters of dense PV demand seem to attract both national- and local-scale installers. Future research may evaluate the role of local installers in PV markets.
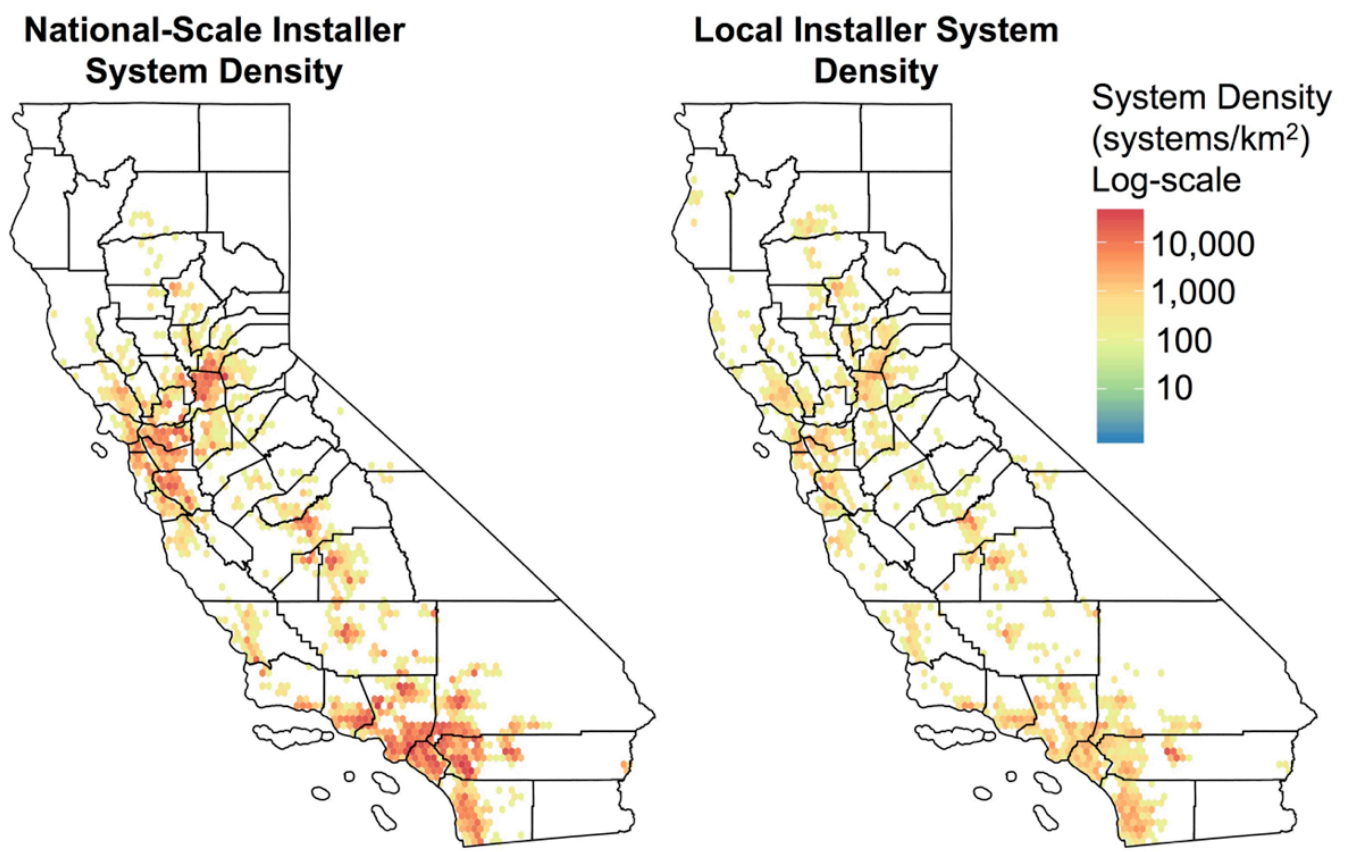

Figure 15. Density (systems $/ \mathrm{km}^{2}$ ) of systems installed by national-scale installer (left map) and local installers (right map) 


\section{Conclusion}

The results illustrate three desirable properties of an installer-based approach relative to a county-level approach to PV market definition:

- The IOC as a metric demonstrates that installers tend to cluster into local communities and installer communities become increasingly dissimilar at greater geographic distances. The implication is that the competitive price influences of installers on one another decline with distance. The IOC approach delineates boundaries around similar installer communities, by definition, and thus identifies areas within which installers exert competitive pressures on other installers within the same market. In contrast, a countylevel approach may arbitrarily group fundamentally dissimilar installer communities into an overly broad market boundary.

- The IOC approach results in far more market granularity than a county-level approach. Greater market granularity can allow future PV market research to study relationships between local market dynamics and pricing with more precision.

- The spatial dependence of market metrics such as installed prices declines with distance. The IOC approach, which generally (though not necessarily) results in geographically smaller markets, is therefore more likely to delineate market boundaries around areas where market metrics are more highly correlated.

This paper seeks to develop a PV market definition approach based on the spatial distribution of local installer communities. The general premise is that PV markets can be inferred from the spatial distribution of unique sets of installers. We develop a new metric, the installer overlap coefficient, to assess the degree to which local installer communities resemble one another. Our market definition approach reveals more market segregation than a market definition based on county-level jurisdictional boundaries, suggesting that market research based on county-level market definitions may overestimate the geographic extent of PV markets. Using the Moran's $I$ test for spatial dependence, we find significant evidence of spatial autocorrelation of PV market prices and installer composition under any market definition. The analysis demonstrates that the installer-based approach to PV market definition has the desirable properties of higher market granularity built around local installer communities. Unlike a county-level approach, the installer-based approach does not force fundamentally dissimilar local markets into a single arbitrary jurisdictional boundary. The greater market granularity achieved by the installer-based approach will allow future PV market research to study relationships between local market dynamics and pricing with more precision. 


\section{References}

Anselin, L. 2001. "Spatial Econometrics." In A Companion to Theoretical Econometrics, edited by Badi H. Baltagi, 310-330. Blackwell Publishing.

Baker, J.B. 2007. "Market Definition: An Analytical Overview." Antitrust Law Journal 74 (1):129-173. doi: http://www.jstor.org/stable/27897544.

Barbose, G., and N. Darghouth. 2015. Tracking the Sun VII: The Installed Price of Residential and Non-Residential Photovoltaic Systems in the United States. LBNL.

Barbose, G., N. Darghouth, S. Weaver, D. Feldman, R. Margolis, and R. Wiser. 2015. "Tracking US photovoltaic system prices 1998-2012: a rapidly changing market." Progress in Photovoltaics: Research and Applications23:692-704. doi: 10.1002/pip.2482.

Beckert, W. 2010. "A Micro-Economic Approach to Geographic Market Definition of Local Retail Markets: Demand Side Considerations." Economics 4:2010. doi: http://dx.doi.org/10.5018/economics-ejournal.ja.2010-29.

Bivand, R.S., E. Pebesma, and V. Gomez-Rubio. 2013. Applied Spatial Data Analysis with R. Vol. 10, Use R! New York, NY: Springer-Verlag New York.

Bivand, R.S., G. Piras. 2015. "Comparing Implementations of Estimation Methods for Spatial Econometrics." Journal of Statistical Software 63 (18):1-36.

Bollinger, B., and K. Gillingham. 2012. "Peer effects in the diffusion of solar photovoltaic panels." Marketing Science 31 (6):900-912.

Boshoff, W.H. 2014. "Market Definition as a Problem of Statistical Inference." Journal of Competition Law \& Economics 10 (4):861-882. doi: 10.1093/joclec/nhu025.

Brooks, G.R. 1995. "Defining Market Boundaries." Strategic Management Journal 16 (7):535549.

Brorsen, B.W., D. Bailey, and M.R. Thomsen. 1997. "Mapping Market Areas Using Nonparametric Smoothing."Geographical Analysis 29 (3):214-231.

Coate, M.B., and J.H. Fischer. 2008. "A Practical Guide to the Hypothetical Monopolist Test for Market Definition."Journal of Competition Law \& Economics 4 (4):1031-1063.

Davis, P., and E. Garces. 2010. Quantitative Techniques for Competition and Antitrust Analysis. Princeton, NJ: Princeton University Press.

Geroski, P.A. 1998. "Thinking creatively about markets." International Journal of Industrial Organization 16:677-695.

Gillingham, K., H. Deng, R.H. Wiser, N. Darghouth, G. Nemet, G.L. Barbose, V. Rai, and C. Dong. 2016. "Deconstructing Solar Photovoltaic Pricing: The Role of Market Structure, Technology, and Policy." The Energy Journal 37 (3):231-250. 
Kaplow, L. 2015. "Market definition, market power." Journal of Industrial Organization 43:148161. doi: http://dx.doi.org/10.1016/j.ijindorg.2015.05.001.

Kate, A., and G. Niels. 2008. "The Relevant Market: A Concept Still in Search of a Definition." Journal of Competition Law \& Economics 5 (2):297-333.

Massey, P. 2000. "Market Definition and Market Power in Competition Analysis: Some Practical Issues." The Economic and Social Review 31 (4):309-328.

Nemet, G., E. O'Shaughnessy, N.R. Darghouth, R.H. Wiser, G.L. Barbose, K. Gillingham, and V. Rai. 2016. Characteristics of Low-Priced Photovoltaic Systems in the United States. Berkeley, CA: Lawrence Berkeley National Laboratory.

Paradis, E., J. Claude, K. Strimmer. 2004. "APE: analyses of phylogenetics and envolution in R language." Bioinformatics 20:289-290.

Perloff, J.M. 2009. Microeconomics. Edited by Pearson Education. 5th Edition.

Werden, G.J. 1981. "The Use and Misuse of Shipments Data in Defining Geographic Markets." Antitrust Bulletin 26 (4):719-737.

Wiser, R., M. Bolinger, P. Cappers, and R. Margolis. 2007. "Analyzing Historical Cost Trends in California's Market for Customer-Sited Photovoltaics." Progress in Photovoltaics: Research and Applications 15:69-85. doi: 10.1002/pip.726. 


\section{Key Report Contacts}

Eric 0'Shaughnessy

National Renewable Energy Laboratory

eric.oshaughnessy@nrel.gov

Gregory F. Nemet

University of Wisconsin at Madison

nemet@wisc.edu

\section{Acknowledgments}

This work was supported by the U.S. Department of Energy's Office of Energy Efficiency and Renewable Energy Solar Energy Technologies Office under Contract No. DE-AC36-08G028308 with the National Renewable Energy Laboratory. For supporting this work, we thank Elaine Ulrich, Odette Mucha, Joshua Huneycutt, Ammar Qusaibaty and the entire DOE Solar Energy Technologies Office team. For reviewing earlier versions of this report, we also thank Jason Brown (Federal Reserve Bank of Kansas City), who provided spatial statistics expertise, and Ryan Wiser (Lawrence Berkeley National Laboratory).

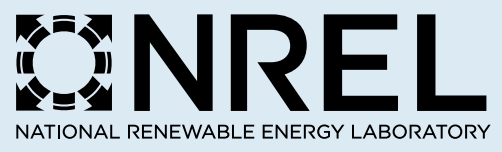

NREL is a national laboratory of the U.S. Department of Energy, Office of Energy Efficiency and Renewable Energy, operated by the Alliance for Sustainable Energy, LLC.

NREL/TP-6A20-66773 • September 2016

NREL prints on paper that contains

recycled content.

\section{Notice}

This report was prepared as an account of work sponsored by an agency of the United States government. Neither the United States government nor any agency thereof, nor any of their employees, makes any warranty, express or implied, or assumes any legal liability or responsibility for the accuracy, completeness, or usefulness of any information, apparatus, product, or process disclosed, or represents that its use would not infringe privately owned rights. Reference herein to any specific commercial product, process, or service by trade name, trademark, manufacturer, or otherwise does not necessarily constitute or imply its endorsement, recommendation, or favoring by the United States government or any agency thereof. The views and opinions of authors expressed herein do not necessarily state or reflect those of the United States government or any agency thereof.

This report is available at no cost from the National Renewable Energy Laboratory (NREL) at www.nrel.gov/publications.

Available electronically at SciTech Connect http:/www.osti.gov/scitech

Available for a processing fee to U.S. Department of Energy and its contractors, in paper, from:

U.S. Department of Energy

Office of Scientific and Technical Information

P.0. Box 62

Oak Ridge, TN 37831-0062

0STI http://www.osti.gov

Phone: 865.576.8401

Fax: 865.576.5728

Email: reports@osti.gov

Available for sale to the public, in paper, from:

U.S. Department of Commerce

National Technical Information Service

5301 Shawnee Road

Alexandria, VA 22312

NTIS http://www.ntis.gov

Phone: 800.553 .6847 or 703.605 .6000

Fax: 703.605 .6900

Email: orders@ntis.gov 